PAUlO DONOSO JOHNSON

(Pontificia Universidad Católica de Valparaíso)

\title{
LA STÁSIS EN LA POESÍA GRIEGA DE LA ÉPOCA ARCAICA (S. VII-VI A.C.)
}

\section{The stásis in the Greek Poetry of the Archaic Era $\left(7^{\text {th }}-6^{\text {th }} B C\right)$}

\begin{abstract}
Stásis as a political phenomenon arises in Archaic Greece as a consequence of the absence of written law, tyrannical governments and the iniquities due to the excessive accumulation of wealth by the aristocratic class. Didactic epic, elegies and iambus describe social unrest in the different póleis. The stásis is narrated, sometimes explicitly, sometimes indirectly, in poems and fragments that transmit the state of permanent conflict during the first centuries of history of the Greek póleis.
\end{abstract}

KEY WORDS: Stásis, archaic Greek poetry, elegies, iambus.

RESUMEN: La stásis como fenómeno político surge en la Grecia Arcaica a consecuencia de la ausencia de leyes escritas, la preeminencia de las tiranías y las injusticias asociadas a la excesiva acumulación de riquezas por parte de los nobles. La épica didáctica, las elegías y los yambos dan cuenta de la agitación social en las distintas póleis. La stásis se narra, a veces explícitamente, a veces de manera indirecta, en poemas y fragmentos que transmiten el permanente estado de discordia de los primeros siglos de historia de las póleis griegas.

Palabras Clave: Stásis, poesía griega arcaica, elegías, yambos.

Fecha de Recepción: 17 de septiembre de 2020.

Fecha de Aceptación: 26 de octubre de 2020.

Lo que realmente une a los griegos no son los dioses sino el Estado. ${ }^{1}$

\section{Introducción}

WiLAMOWITZ DEFINE EN ESTE ENUNCIADO UNO DE LOS ÁMBITOS MÁS importantes del pasado griego. ${ }^{2}$ Es durante la era arcaica cuando se sientan las bases de las principales reformas políticas que posibilitarán el acceso al poder de grupos sociales no considerados por siglos en el juego político. La poesía lírica arcaica tendrá un rol sustantivo en la construcción retórica de la justicia como camino inequívoco de equidad y también advertirá de los principales problemas que devienen de la

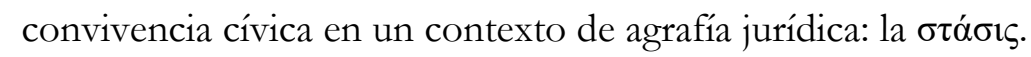

\footnotetext{
1 Wilamowitz-Moellendorff (1912: 12).
}

2 Este artículo está asociado al proyecto FONDECYT INICIACIÓN No 11190280 "Democracia y Stásis: La disidencia en la Grecia Clásica, s. VI-IV a.C.” adjudicado por concurso público a través de la Agencia Nacional de Investigación y Desarrollo de Chile (2019-2022). 
Es mi propósito en este trabajo analizar la complejidad histórica y literaria de la

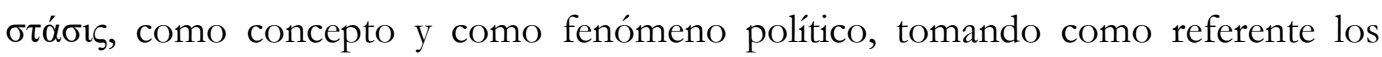
textos y fragmentos de la poesía griega arcaica que la mencionan. Mi punto de vista pretende resaltar la tendenciosidad de los textos conservados que desde el lenguaje moderaron las reales consecuencias de este fenómeno político. ${ }^{3}$

\section{Definir la $\sigma \tau \alpha \dot{\sigma} \sigma \varsigma$}

Este concepto polisémico ha sido estudiado e interpretado desde distintos puntos de vista. En época arcaica se advierten términos afines como $\dot{\varepsilon} \mu \varphi v \lambda i ́ \alpha$, y otros

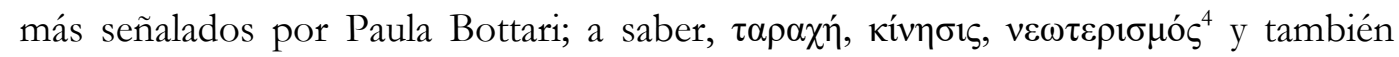
$\dot{\varepsilon} \pi \alpha v \alpha ́ \sigma \tau \alpha \sigma 1 \varsigma .{ }^{5}$ Sin embargo, la stásis en sí misma comporta un sentido político cuyo

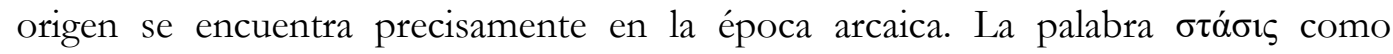
deverbativo de í $\tau \tau \eta \mu$, aparece sólo a partir del siglo IV a.C., mientras que el "uso según el valor intransitivo, paralelo a ĩ $\tau \alpha \mu \alpha$, es evidenciado en la lírica arcaica". ${ }^{6} \mathrm{El}$ verbo $\sigma \tau \alpha \sigma i \alpha ́ \zeta \omega$ indica quietud, inmovilidad. ${ }^{7}$ ¿Por qué entonces un verbo que señala la ausencia de movimiento se transforma entonces en el principal concepto político para definir disidencia, conflicto civil, lucha armada política, revolución y golpe de estado? El carácter polisémico del término se verifica con mayor énfasis durante la era clásica, cuando la violencia política se enquista en el seno de la pólis, debido al protagonismo de la facción popular democrática sobre las viejas aristocracias.

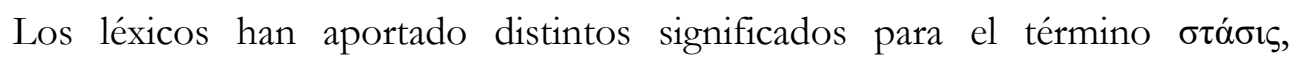
tomando referencias de los textos clásicos y dando cuenta de sus diversos y amplios significados. Así Chantraine destaca el valor político del término en tanto división y

${ }^{3}$ Cartledge (1998: 786): “There is easily detectable in much Greek thinking, not only political, an all-pervasive conservatism. Greek often found themselves or perceived themselves as being in the grip of the past, with the linguistic consequence that political ideas and practices which we might want to label positively as "revolution" such as the invention of democracy, they would habitually and automatically anathematize as "new" or "newer things", opposing them unfavourably to that which was traditional ( $\pi \alpha \tau \rho i ́ o v) . ”$

${ }^{4}$ Bottari (1989: 90).

${ }^{5}$ Manolopoulos (1991).

${ }^{6}$ Radici-Sergi (2000: 223).

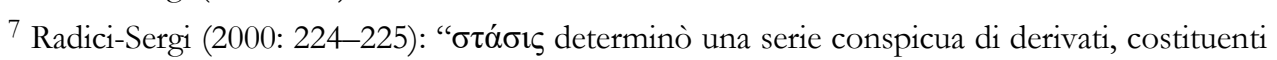

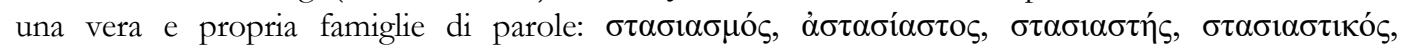

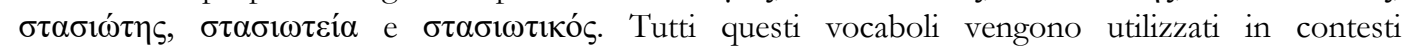
exclusivamente politici o che, comunque, concernono situazioni di contrasto analoghe a quella di una lotta politica. Il derivato $\sigma \tau \alpha \sigma i \omega \tau \eta \varsigma$, ad esempio, bien fatto valere sempre come compagno di fazione, partigiano o sedizioso." Vid. Loraux (2008: 68). 


\section{TALIA DIXIT 15 (2020), 1-31}

facción, ${ }^{8}$ mientras que Liddell-Scott y Montanari lo identifican directamente con la sedición, la lucha, la discordia y el enfrentamiento. ${ }^{9}$

Desde la perspectiva histórica y política, se ha definido la stásis desde diversas líneas historiográficas que permean inevitablemente la lectura del pasado griego. Así, cuando la guerra ( $\pi$ ó $\varepsilon \varepsilon \mu \rho \varsigma)$ como fenómeno es analizada por Moses Finley como un "factor básico de crecimiento que permite la transformación de la estructura social", ${ }^{10}$ abre una línea de análisis que se cristaliza en la propuesta de Ste. Croix según la cual "la stásis como conmoción civil era básicamente una cuestión de clases sociales". ${ }^{11}$ Santo Mazzarino en cambio le otorga a las luchas civiles un lugar privilegiado en el contexto de las revoluciones espirituales y religiosas del siglo VI a.C. que dan lugar a profecías sobre el pasado, ergo, el origen de la historia. ${ }^{2}$ Mogens H. Hansen y Thomas H. Nielsen, a partir de los episodios transmitidos por textos históricos y epigráficos, concluyen que la stásis es un aspecto esencial de la polis. ${ }^{13}$ Paola Radici, por su parte, dice que el "marco semántico e histórico de la stásis es aplicable siempre y sí y sólo sí se da en el ámbito cívico de la pólis". ${ }^{14} \mathrm{Y}$, según Berent, "puede variar de acuerdo a la horizontalidad y verticalidad de las luchas sociales". ${ }^{15}$ De esta manera podemos advertir, por una parte, formas de stásis entre las clases dominantes o aristocráticas, cuyos modos de comportamiento implican el asesinato político de líderes de los bandos opositores, mientras que, por otra parte, la stásis popular se traduce en revueltas de las masas y movilizaciones sociales. ${ }^{16}$ En este sentido, para la época arcaica, algunos estudios han apuntado en asociar el origen de la stásis con la tiranía, sus formas de acceso al poder y las frecuentes revueltas que precipitaban sus caídas. ${ }^{17}$

La stásis es también un fenómeno antropológico y filosófico. Nicole Loraux hizo lecturas de episodios de la tragedia ática en donde la stásis, como guerra civil, divergencia y caos, emancipa las peores conductas humanas cuando se trata de guerras fratricidas y entre iguales. El conflicto civil que nace en el oikos desnaturaliza

\footnotetext{
${ }^{8}$ Chantraine (1999: 1044).

${ }^{9}$ Liddell-Scott (1996: 1634); Montanari (2013: 2199).

10 Finley (1985: 74).

11 Ste Croix (1988: 66-67). En el Sożiale Typenbegriffe, editado por Welskopf (1985), está
} ausente el término stásis.

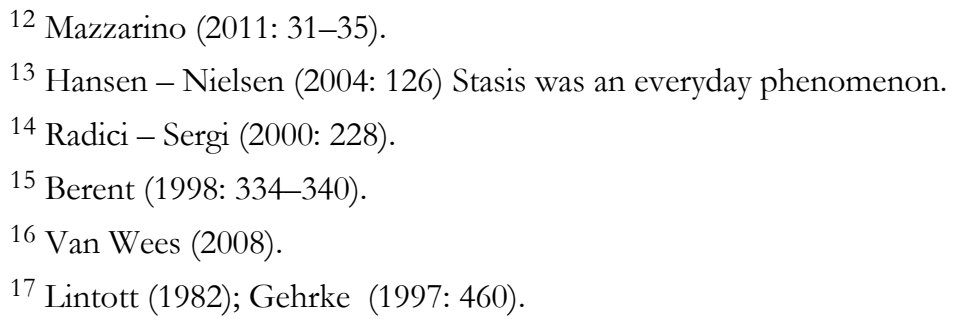


la conducta humana dando paso a episodios de antropofagia, vejaciones inhumanas y ultrajes que colocan al ser humano al límite entre civilidad y salvajismo. ${ }^{18}$

Con la instalación de la democracia en el siglo $\mathrm{V}$ a.C., entendida esta última como un dispositivo de guerra en un contexto belicista, la stásis se convierte en una verdadera catástrofe para la comunidad. ${ }^{19}$ De esta forma, la stásis deviene en un acontecer trágico en el ámbito público. En suma, y en palabras de Mauro Moggi, "un fenómeno funesto e inevitable". ${ }^{20}$

Finalmente, la definición propuesta por Emanuele Stolfi es -a mi parecer- la que interpreta de mejor manera la intensidad del concepto:

Stásis è parola bellissima e terribile: assente in Omero ed Esiodo, ma attestata già in Alceo e Solone, essa designa dapprima la semplice 'posizione', quindi il 'partito' - il gruppo di persone che, appunto, prendono posizione e si contrappongono ad altri infine la sedizione interna alla pólis e la guerra civile: un'autentica 'peste' que contamina la città. ${ }^{21}$

\section{Las motivaciones de la $\sigma \tau \alpha \dot{\sigma} \iota \varsigma$ en la Grecia arcaica. Sentencias torcidas e injustas}

Es indispensable dar cuenta de uno de los principales problemas de la vida en comunidad: la convivencia. La realidad urbana de las póleis griegas durante la era arcaica no era homogénea. Mientras Mégara, Atenas y Corinto eran las ciudades comerciales por excelencia, ${ }^{22}$ ciudades como Atenas, Corinto y Mileto eran a su vez las más cultas hacia el siglo VI a.C. ${ }^{23}$ El resto de las póleis griegas vivían procesos distintos, con mayor predominancia agrícola que urbanas, con sistemas monárquicos de gobierno de carácter dual como Esparta o tiránico, como sucedía en Atenas y en las colonias en Sicilia entre otras. Estos regímenes políticos, que Julián Gallego ha definido como "un ejercicio de la basileía en tres planos de organización social: oíkos, kóme, pólis", ${ }^{24}$ no siempre dieron respuesta al principal problema que anidó en este período: la concentración de la riqueza y de las tierras cultivables en manos de las

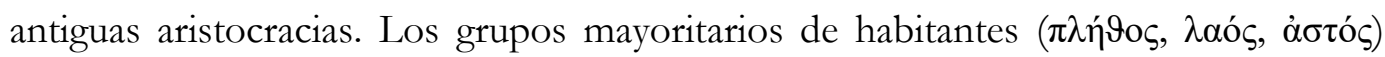

18 Loraux (1995); Loraux (2008).

19 Arancibia Carrizo (2020: 82-104).

20 Moggi (2012: 150): "Non credo che esistano deroghe alla rappresentazione negativa del conflitto intestino e soprattutto non credo che quest'ultimo possa essere visto como un fattore positivo, che, in una società improntata all'agonismo e alla competizione, sarebbe stato in grado di contribuire in misura rilevante alla coesione e alla solidità delle singole comunità".

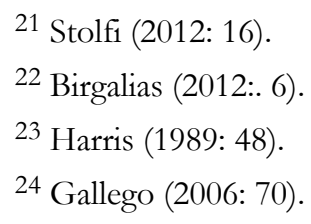


reivindicaron reformas bajo la forma de stásis, rompiéndose así la concordia entre

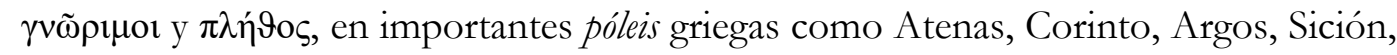
Mégara, Samos, Mitilene, Mileto y Paros. ${ }^{25}$ Esta causalidad de la stásis y su origen en la concentración de la riqueza y la tierra se transformará en el principal argumento retórico del siglo IV a.C., tal y como puede observarse en los tratados aristotélicos. ${ }^{26}$ Sin embargo, los textos y fragmentos conservados de los siglos VII y VI a.C. enfatizan el complejo y endémico fenómeno de la stásis desde una dimensión moral más que política, donde el problema de la ausencia de leyes escritas y la arbitrariedad de las sentencias de los reyes-jueces enfrenta a los distintos grupos sociales en luchas intestinas y en discordia.

En este contexto la poesía griega advierte fuertes oposiciones sociales que convulsionan la paz y la estabilidad. La filosofía de Heráclito influirá enormemente en el pensamiento político de la era arcaica y particularmente en los autores del siglo VII a.C. ${ }^{27}$ Uno de los aspectos más destacables hasta antes de las reformas de Solón era la ausencia de palabras que dieran cuenta del ciudadano como actor político relevante en el gobierno de la ciudad. Así, Arquíloco utiliza términos como ảotó $\varsigma^{28}$, $\lambda \imath \pi \varepsilon \rho v \tilde{\eta} \tau \varepsilon \varsigma \pi \mathrm{o} \lambda \tilde{\tau} \tau \mathrm{r}^{29}$ y $\delta \tilde{\eta} \mu \varsigma^{30}$ para el caso del pueblo, aunque el concepto predominante desde los poemas homéricos fuese el de $\lambda \alpha$ ós. $^{31}$

En toda la obra homérica no se evidencia el uso de la palabra stásis. No obstante, se han realizado lecturas de pasajes homéricos que dan cuenta de episodios revolucionarios tanto en la Ilíada como en la Odisea, sobre los cuales no profundizaré en este artículo. ${ }^{32}$

25 Birgalias (2012: 8-9). El Copenhagen Polis Center, incluye además a la póleis sicilianas y de Magna Grecia con mayores episodios de luchas civiles entre los siglos VIII y VI a.C. Vid. HansenNielsen (2004: 1361-1362).

26 Arist. Pol. V, 1302a 15; 1302b; 1303a; 1303b; 1304a; 1304b.

27 Heraclit. Fr. 80. Orígenes, C. Celsum, VI 42: Conviene saber que la guerra es común (a todas las cosas) y que la justicia es discordia y que todas las cosas sobrevienen por la discordia y la necesidad. Trad. J. García Fernández.

28 Archil. Fr. 7, 1 D; Fr. 88, 4 D; Fr. 109 D; Fr. 64, 1 D.

29 Archil. Fr. 52 D.

30 Archil. Fr. V 85D.

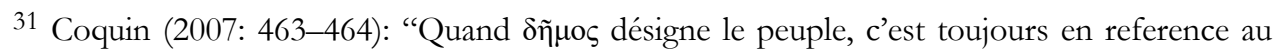
territoire occupé et il est bien difficile parfois de décider s’il est préferable de traduire $\delta \tilde{\eta} \mu \circ \varsigma_{\text {par "le }}$ pays" ou par "le peuple". Par opposition, $\lambda \alpha$ ó $\varsigma$ est le peuple consideré indépendamment de tout ancrage territorial. C'est le people qui est convoqué à l'assamblée, qui se réunit bruyamment, qui agit derrière ses chefs". Weslkopf (1985: 1136-1145) identifica el recurrente uso del término en Homero, Hesíodo, Calino, Tirteo, Alceo, Simónides, Timoteo y Teognis.

32 Van Wees (2008: 20 y ss) advierte que en Odisea hay pasajes que evidenciaban la violencia ejercida desde los sectores populares o pobres hacia sus líderes. Courtieu (2020) analiza en Odisea el primer movimiento revolucionario de Occidente. 


\section{TALIA DIXIT 15 (2020), 1-31}

La palabra stásis no está presente en ninguna de las obras conservadas de Hesíodo. Sin embargo, en Trabajos y Dias se advierten los primeros síntomas del conflicto social. Su vivencia personal como habitante de Ascra, una aldea perteneciente a la pólis de Tespias, en Beocia, y las injusticias y casos de corrupción que les perjudicaban habían llevado a su revolucionario hermano Perses a emprender una lucha política contra el basileús. Hesíodo dedica Trabajos y Días a su hermano con

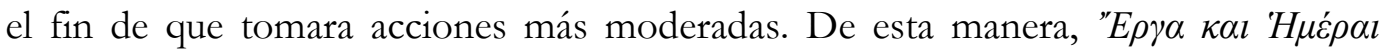
puede ser considerado el primer tratado político de Occidente sobre la discordia y la disidencia.

Un célebre pasaje de Trabajos y Días da cuenta del contexto en el que vive el poeta de Ascra:

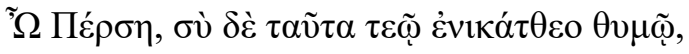

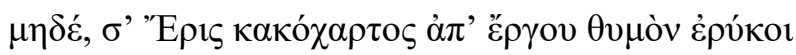

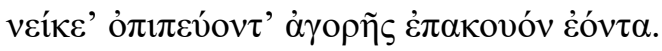

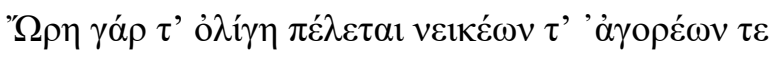

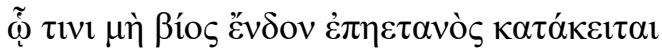

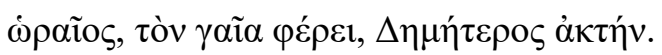

¡Oh Perses!, grábate tú esto en el corazón y que la Eris gustosa del mal no aparte tu voluntad del trabajo, preocupado por acechar los pleitos del ágora; pues poco le dura el interés por los litigios y las reuniones públicas a aquel en cuya casa no se encuentra en abundancia el sazonado sustento, el grano de Deméter, que la tierra produce $(. . .)^{33}$

Es muy relevante el contexto político que el poeta describe. Más allá de la reprimenda al hermano por dedicarse a las cosas políticas en vez del trabajo agrícola,

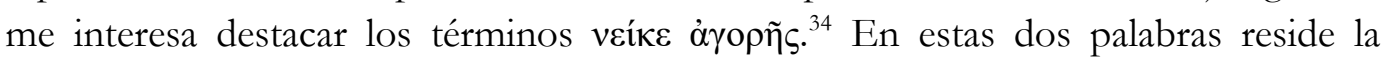
primera descripción de la vida política de la era arcaica. El uso del término veĩкo cuyo significado remite a la disputa verbal y física, que puede conllevar insultos, es la imagen que el poeta quiere transmitir de la acción política, dentro del espacio público del ágora, que en esta época comienza a cobrar forma. Es el momento en que la palabra hablada deja de ser solamente vector de poemas y mitos, sino que se transforma en la principal herramienta de aquello que los antiguos griegos llamaron $\dot{\alpha} \gamma \omega \dot{v} .^{35}$

${ }^{33}$ Hes. Opera et Dies, 28-34. Trad. A. Pérez Jiménez

${ }^{34}$ Hes. Opera et Dies, 29. Trad. A. Pérez Jiménez

35 Stolfi (2012: 8): "la peculiare agonalità, assunse nel vissuto greco, in riferimento tanto a vicende istituzionali - ove la guerra, e costituiva una presenza constante, avvertita come affatto naturale". Gehrke (1997: 453) ve en $I l$. VI, 208 lo que mueve a toda la historia griega: ser el mejor y superar a los otros. 


\section{TALIA DIXIT 15 (2020), 1-31}

La pérdida del valor de la amistad es uno de los aspectos que inciden, según Hesíodo, en la quiebra de la convivencia cívica. La amistad como valor político, privado y público es según David Konstan elemental en la ciudad-estado. De hecho, "en las relaciones de amistad se articulan las esferas entre el hogar individual y la sociedad cívica, regulados por sentimientos más que por leyes de propiedad y derechos políticos". ${ }^{36}$ Hesíodo cree profundamente en el respeto y en la hospitalidad hacia el amigo, tema en el que se detiene en los versos 343-356, 370-373 y 708-718. La amistad en época homérica, donde pí $\lambda$ os y $\varphi \imath \lambda \hat{\varepsilon} \omega$ no tienen el significado de amistad, sino que, en palabras de Arthur W. Adkins, "implican una relación de carácter objetivo que puede referirse desde el desempeño de servicios útiles hasta la inclusión de un ajeno en el círculo íntimo donde sus miembros se apoyan mutuamente". ${ }^{37}$ María Montes Miralles, tomando la premisa de Adkins, cree que la amistad está fuertemente vinculada a la ausencia de daño entre pares. Así, la autora define $\varphi \imath \lambda \varepsilon \dot{\varepsilon} \omega$ como "tratar de modo no hostil a alguien, mientras que pí $\lambda \varsigma_{\varsigma}$ es aquel con el que se mantiene una relación no hostil". ${ }^{38}$

Un aspecto interesante de la épica didáctica de Hesíodo $^{39}$ es el apego a la tradición y el mantenimiento del status quo aristocrático a consecuencia del proceso de sinecismo y de la integración de las aldeas a las póleis. ${ }^{40}$ En Hesíodo, la fábula del halcón que lleva entre sus garras al ruiseñor es un ejemplo acerca del poder y de la fuerza que suelen tener los poderosos y la temeridad de los débiles. Sus primeros versos dicen:

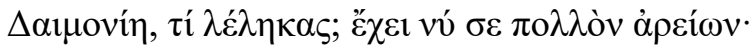

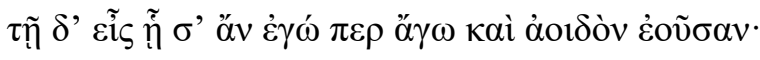

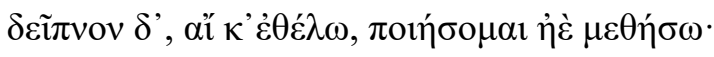

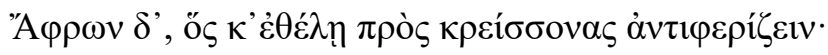

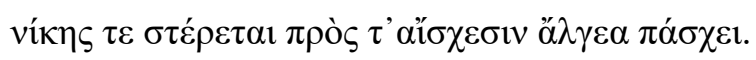

¡Infeliz! ¿Por qué chillas? Ahora te tiene en su poder uno mucho más poderoso. Irás a donde yo te lleve por muy cantor que seas y me servirás de comida si quiero o te dejaré libre. jLoco es el que quiere ponerse a la altura de los más fuertes! Se ve privado de la victoria y además de sufrir vejaciones, es maltratado. ${ }^{41}$

36 Konstan (1997: 44).

37 Adkins (1963: 33-45).

38 Montes Miralles (2006: 38-39).

${ }^{39}$ Harris (1989) sugiere que Hesíodo es además precursor de la poesía gnómica mientras que Vottéro (2020: 160) destaca su primacía como primer mitógrafo y primer pensador social conocido.

40 Gallego (2017: 146) cree que el proceso de sinecismo entraña necesariamente una dominación aristocrática que implica control político y dependencia económica de los labradores.

${ }^{41}$ Hes. Opera et Dies. 207-212. Trad. A. Pérez Jiménez. 
Esta fábula hesiódica puede tener muchas lecturas. Se advierte la consciencia del poeta sobre las limitaciones políticas del pueblo $\left(\lambda \alpha \alpha_{\varsigma}\right)$, la lucha por la mayor libertad de la villa de Ascra ante su poderosa dominadora ciudad-estado beocia de Tespias y también la aceptación de un orden natural en el que el más fuerte prevalece, incluso en el ámbito de la vida ciudadana. Lo que es evidente es que, pese a los consejos y reprimendas de Hesíodo a Perses, el aedo parece valorar la valentía de su hermano.

Dicho esto, y posterior a la fábula, Hesíodo elabora una profunda reflexión en la digresión acerca de la justicia en la ciudad, única vía para el que débil (ruiseñor) pueda escapar de las garras de su poderoso y opresor captor (halcón):

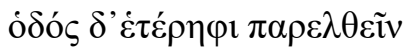

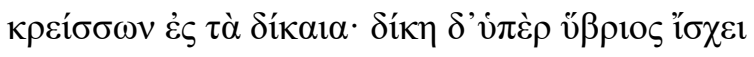

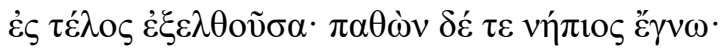

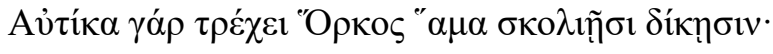

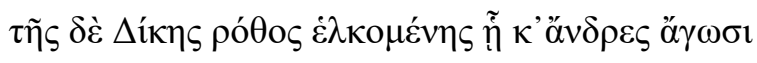

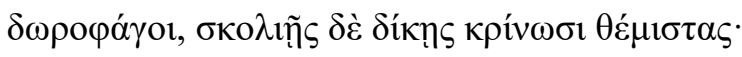

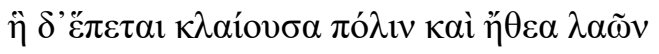

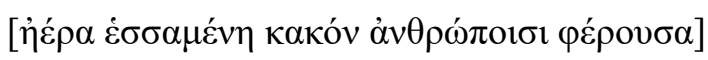

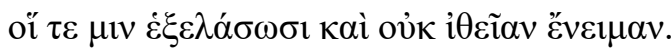

Preferible el camino que, en otra dirección, conduce hacia el recto proceder; la justicia termina prevaleciendo sobre la violencia, y el necio aprende con el sufrimiento. Pues al instante corre el Juramento tras de los veredictos torcidos, cuando la Dike es violada, se oye un murmullo allí donde la distribuyen los hombres devoradores de regalos e interpretan las normas con veredictos torcidos. Aquella va detrás quejándose de la ciudad y de las costumbres de sus gentes envuelta en la niebla, y causando mal a los bombres que la rechazan y no la distribuyen con equidad. ${ }^{42}$

Este pasaje, que ha tenido diversas interpretaciones, ${ }^{43}$ plantea dos aspectos de la sociedad griega arcaica que fomentaban las luchas intestinas: la justicia no es igual para todos, con especial detrimento para los pobres, y los reyes son los encargados

42 Hes. Opera et Dies. 213-224. Trad. A. Pérez Jiménez.

43 Colombani (2018: 9) La fábula del gavilán y el ruiseñor es "el no reconocimiento del otro como persona, anclado en una lógica del tener, lo cuál supone apropiarse del otro, representándolo mentalmente como un objeto (...) es una operación de despersonalización, donde el otro, el prójimo, el amigo, el pariente, el vecino se convierte en una cosa que pierde su registro antropológico". 
de impartir la justicia. Para Hesíodo hay dos caminos (ódós) ${ }^{44}$ que colocan a los

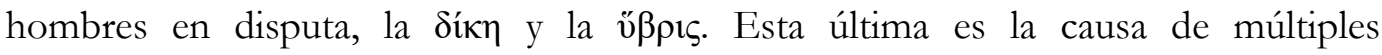

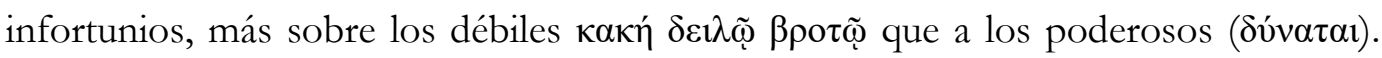
La justicia en cambio permite erradicar la violencia y castiga con el sufrimiento

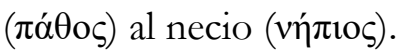

El verso 220 es probablemente una de las más notables descripciones del funcionamiento de una sociedad sin leyes escritas y a expensas de monarcas y tiranos cuyos intereses particulares se entrelazan con el otorgamiento de sentencias judiciales ambiguas e injustas.

El elaborado recurso metafórico político de Hesíodo se presenta en sus ö $v \delta \rho \varepsilon \varsigma$ $\delta \omega \rho$ justicia: ${ }^{45}$

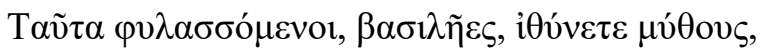

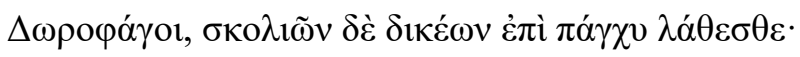

Teniendo presente esto, ;reyes!, enderezad vuestros discursos, ;devoradores de regalos!, y olvidaros de una vez.por todas de torcidos dictámenes. ${ }^{46}$

La descripción hesiódica evidencia la difundida práctica de los reyes y tiranos por recibir donativos de todo tipo para dictar sentencias favorables. Esta práctica permitirá que las clases dominantes y aristocráticas no recibieran sentencias de la misma manera a la que un ciudadano empobrecido, un campesino o un esclavo pudieran aspirar. Esta desigualdad ante la ley es advertida por Hesíodo, quien, viviendo en carne propia las vejaciones a la que estaba sometida una villa como Ascra y sus habitantes, interpela al centro político de Tespias, desde donde emanaban todas las ordenanzas y fallos judiciales.

Siguiendo a William Harris, para quien la poesía hesiódica no consiste en poemas para agricultores sino que es precursora de la poesía de sentencias sabias o gnómica, ${ }^{47}$ es posible advertir también un diagnóstico político y social de las injusticias a las que se veían sometidos los habitantes de las póleis griegas. La pobreza de muchos habitantes, que viven en el desamparo y bajo el arbitrio de gobernantes

${ }^{44}$ Recurso retórico del mundo binario que utilizará Parménides en su proemio y Pitágoras en el siglo VI a.C. y Esquilo en su tragedia Los Persas, en el sueño de Atosa, en el siglo V a.C. Para Gentili (1996: 138) la metáfora del camino es un topos recurrente en la lírica coral.

45 Hesíodo presenta su protesta política en la primera parte de su obra, mencionado a los

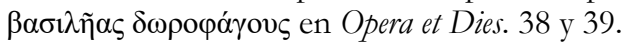

${ }^{46}$ Hes. Opera et Dies, 264-265. Trad. A. Pérez Jiménez.

${ }^{47}$ Harris (1989: 49). 
injustos hambrientos de riqueza, le lleva a componer el más importante tratado de la era arcaica sobre el trabajo agrícola y la economía doméstica. Un Hesíodo que los insta a sobrellevar una existencia sin leyes justas, en la espera de que los dioses algún día reviertan esta situación y los reyes injustos sufran el castigo por sus malas acciones y por la bybris.

En definitiva, si bien la stásis no aparece en la obra de Hesíodo, sí es posible establecer en las advertencias del poeta de Ascra la tensión social debida a la ausencia de justicia como el germen de revueltas y convulsión política, aspecto señalado por Hans Van Wees. ${ }^{48}$ Es precisamente su hermano Perses la figura que Hesíodo intenta controlar, siendo la personificación de la stásis muda, no revelada, que subyace en el alma de las ciudades y villas rurales que sufren la injusticia.

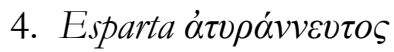

La constitución espartana de Licurgo, transmitida a través de la Eunomía de Tirteo (s. VII a.C.) ordena el mundo de la era arcaica de la siguiente manera:

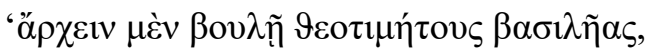

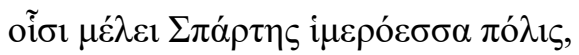

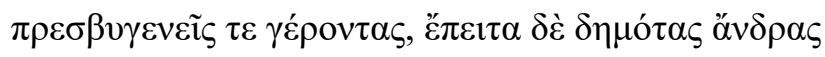

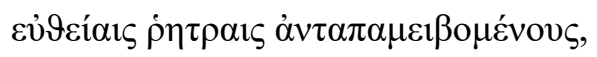

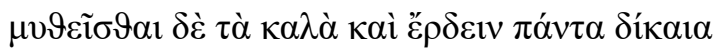

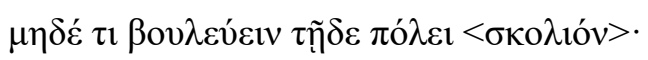

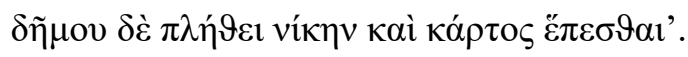

Que gobiernen con su consejo los reyes honrados por los dioses, bajo cuyo mando está la hermosa ciudad de Esparta, asi como los ancianos, de antiguo nacimiento, y, después, los hombres del pueblo, respondiéndoles con decretos justos; y que no sólo pronuncien palabras honorables, sino que también obren siempre la justicia; y que no decidan ninguna cosa torcida con daño de la ciudad; pero que la victoria y la decisión final sea del pueblo. 49

Este texto en verso es la primera politeía del mundo griego y posiciona al pueblo espartano en una privilegiada posición deliberativa. El carácter viril de estos $\delta \eta \mu o ́ \tau \alpha \varsigma ~ \alpha ̋ v \delta \rho \alpha \varsigma$, cuyo rol político es evitar la aprobación de leyes torcidas que

48 Van Wees (2008: 5 - 6): “Hesiod's Works \& Days is not really a poem about agriculture. As the opening lines show, it is a poem about competition (eris), almost half of which is devoted to warnings against the bad kind of competition which promotes harmful war and conflict. In Hesiod's Theogony, is also beset by conflict, violence and deceit. This poem's pièce de résistance is a detailed account of the battle between two generations of gods, the Titans against Zeus and his allies."

49 Tyrt. Fr. 3. Trad. F. Rodríguez Adrados. 


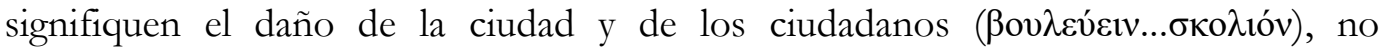
significa que el pueblo en sí haya sido un actor privilegiado en el ejercicio del poder. El gran problema de la sociedad griega arcaica es la justicia y la experiencia jurídica sin juristas. ${ }^{50}$ Este último aspecto será el motor de las grandes revueltas y conflictos de las sociedades arcaicas, pues el magistrado era en primer y en último término el basileuis.

Es muy interesante constatar que tanto en una potencia militar como era Esparta como en la agreste y sometida Ascra, Tirteo y Hesíodo dan cuenta del potencial motivo del descontento popular en la era de la ley ágrafa a través de las

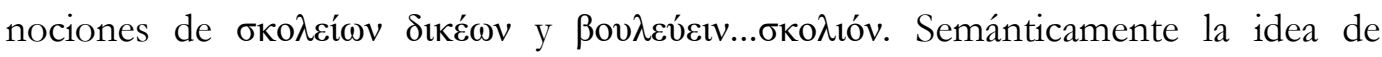

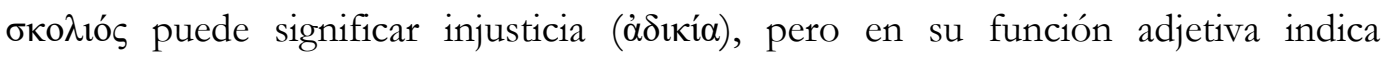
oblicuidad, torsión (tanto corporal como metafórica) y también crueldad e inequidad. Son entonces las sentencias arbitrarias de un magistrado-basileús que se corrompe con regalos poniendo en riesgo una sentencia favorable para los más pobres $(\lambda ı \pi \varepsilon \rho v \tilde{\eta} \tau \varepsilon \varsigma$ $\pi \mathrm{o} \lambda \tau \tau \alpha l)$ una causa de descontento y stásis. Por otro lado, la eunomía de la Rhetra espartana que transmite Tirteo surge precisamente a partir de muy antiguos episodios de stásis, narrados por Heródoto ${ }^{51}$ y Tucídides, quien la describe de la siguiente manera:

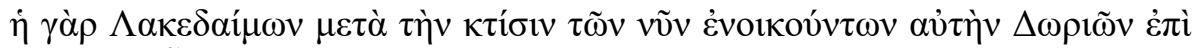

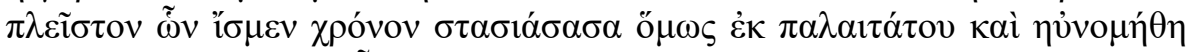

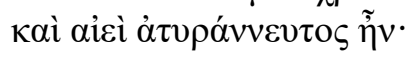

Lacedemonia, después de su fundación por los dorios, que la siguen babitando actualmente, aunque fue, de los que conocemos, el país que sufrió disensiones internas durante más tiempo, sin embargo desde muy antiguo tuvo buenas leyes y siempre se vio libre de tiranos. ${ }^{52}$

El discurso político espartano que sustenta su hegemonía durante toda la era arcaica y clásica es precisamente su condición de polis àtupóvvevioç. No así la stásis, que reside en el seno de una sociedad fuertemente jerárquica y que la Rhetra intenta enmendar, como constitución política pero además como artilugio discursivo de una potencia hegemónica y silenciosa. ${ }^{53}$ Lo que Martin Dreher ha denominado "la paradoja del kosmos espartano, que era estable por su estado de peligro

50 Stolfi (2020: 44 y ss).

51 Hdt. 1, 65, 2: “... tuvieron las peores leyes de casi toda Grecia, tanto en sus relaciones internas como en su aislacionismo con los extranjeros".

52 Thuc. 1, 18, 1. Trad. J. J. Torres Esbarranch.

53 D'Alessio (2009: 156): "Somewhat paradoxically, an authoritative voice impersonating an undivided polis would often have more easily been the product of a foreign personality, not directly implicated in any of the competing political groups". 
permanente", ${ }^{54}$ y que la poesía de Tirteo, un aedo extranjero, intentó crear "con un discurso unificado de identidad para la comunidad", según Giovan Battista D'Alessio. ${ }^{55}$

La historia y la literatura del mundo griego arcaico reside en sus pocos fragmentos poéticos conservados de los siglos VII y VI a.C. y en una muy extensa tradición literaria de los siglos V y IV a. C que moderaron, matizaron e idealizaron este período preñado de violentas revueltas y grandes injusticias. Esta idea es recogida por Alessandro Iannucci quien cree que "la poesía de Homero y Tirteo, en donde el culto al héroe y a la guerra, junto al éthos de la muerte, tienen un uso propagandístico con el fin de persuadir a los jóvenes hoplitas a caer en el campo de batalla, aspirando al $x \lambda$ éos. Esta poesía habría sido útil para el engaño de un grupo dominante, la aristocracia de las primeras póleis y luego la oligarquía de la era clásica, que les permitirá perpetuar la propia hegemonía social, económica y política" ${ }^{\text {56. Una }}$ visión distinta propone Simon Hornblower, para quien no es tan evidente que la poesía lírica griega haya sido escrita por y para las élites. La relación que había entre autócratas individuales poderosos y poetas líricos en el período arcaico, no necesariamente influía en sus creaciones, puesto que el poeta elige si validar o no el orden social que celebra. ${ }^{57}$

\section{La alegoría de la stásis en la Nave del Estado}

El simposio es sin lugar a dudas el espacio de transmisión de la poesía arcaica. ${ }^{58}$ Massimo Vetta recrea este espacio intelectual y político como "el lugar del honor y del deshonor, el lugar del conservadurismo aristocrático, que se opone a las sillas públicas funcionales de la democracia y al teatro". ${ }^{59}$ Es también el espacio que antecede y da curso a la guerra ${ }^{60}$ y el lugar del intercambio político, el conflicto ideológico y la stásis.

A fines del siglo VII a.C. en Mitilene, tierra de insignes poetas como Safo y Alceo, este último, según Fernando García Romero, "descubre un mundo literario distinto, el mundo del banquete, de las conspiraciones políticas y las enconadas y con

\footnotetext{
54 Dreher (2009: 64).

55 D'Alessio (2009: 156).

56 Iannucci (2017: 43).

57 Hornblower (2009: 50 - 51). Esta representación la realiza a partir de la poesía pindárica,

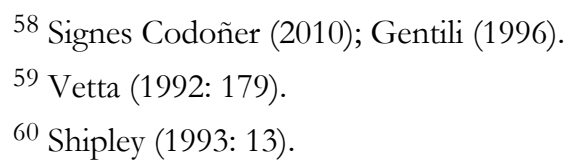
un poeta no aristocrático. 


\title{
TALIA DIXIT 15 (2020), 1-31
}

frecuencia crueles luchas entre los partidos". ${ }^{61}$ En este ambiente de creación y de enconadas luchas partidistas, "la nave del estado, es usada como alegoría para referirse a su natal Mitilene, y su estabilidad puesta a prueba por las luchas entre las distintas facciones políticas" ${ }^{\prime 62}$ son parte de su interesante corpus de metros en estrofa alcaica, y presentamos la primera estrofa:

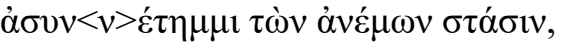

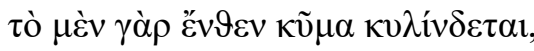

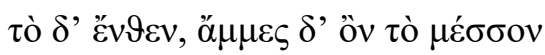 vãi $\varphi о \rho \eta ́ \mu \varepsilon \vartheta \alpha$ бòv $\mu \varepsilon \lambda \alpha i ́ v \alpha \imath$

\begin{abstract}
No entiendo la lucha intestina de los vientos, porque una ola rueda de un lado $y$ otra de otro, y nosotros hacia el medio del mar somos arrastrados junto con la nave negra. ${ }^{63}$
\end{abstract}

Un análisis pormenorizado de este pasaje como directa alegoría de la discordia civil fue realizado por Bruno Gentili en su riguroso análisis sobre el origen de la pragmática de la alegoría de la nave ${ }^{64}$ y Francisco Rodríguez Adrados vio en la alegoría de la nave de Alceo la destrucción del viejo orden aristocrático. ${ }^{65}$

En la poesía conservada de Alceo, entre sus versos eróticos e himnos, destacan los llamados $\Sigma \tau \alpha \sigma i \omega \tau$ iká o cantos revolucionarios, un género que promovió una visión política muy activa, que convive con los versos idílicos y el ideal de la moderación homérica. ${ }^{66}$ Alceo, vivió la stásis y la fuerte lucha de facciones de los partisanos de Pítaco y Mirsilo, a quienes dedica duras sentencias en sus poemas. Alceo será testigo privilegiado y autor contemporáneo del rápido cambio de regímenes políticos que vive la isla, de la monarquía a la tiranía y de la oligarquía a la democracia. ${ }^{67}$

\footnotetext{
${ }^{61}$ García Romero (2017: 189).

${ }^{62}$ García Romero (2017: 190).

${ }^{65}$ Rodríguez Adrados (1955: 210).

${ }^{66}$ Rodríguez Adrados (1959: 88).

${ }^{67}$ Dimopoulou (2019: 33-34).
}

${ }^{63}$ Alc. Fr. 208 Voigt, Trad. F. García Romero.

${ }^{64}$ Gentili (1996: 405 - 439). Esta alegoría metafórica también es utilizada por Heráclito, All. Hom. 5, 5-9; Teognis y Esquilo. El Fr. 11 D de Solón también apunta a esta alegoría cuando describe el mar embravecido por los vientos, como alegoría del pueblo ateniense. 


\section{TALIA DIXIT 15 (2020), 1-31}

Uno de los rasgos distintivos de la poesía de Alceo es que habla en clave contemporánea, declamando sus cantos revolucionarios en los simposios, atiborrados de partisanos de los bandos en disputa, aquello que Bruno Gentili definió como poesía nacida en la acción y para la acción. ${ }^{68}$ Así, lo manifiesta en el siguiente fragmento:

$$
\begin{aligned}
& \text { [_][] ].[.].Х...[ }
\end{aligned}
$$

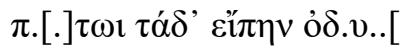

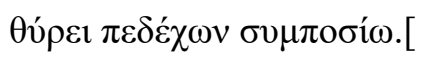

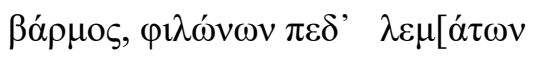

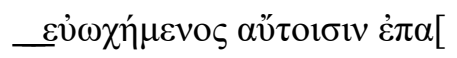

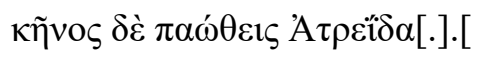

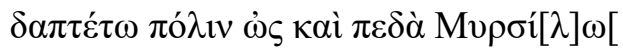

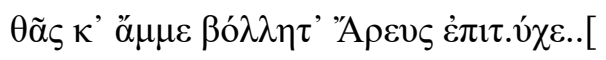

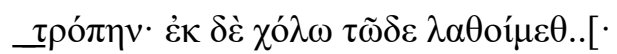

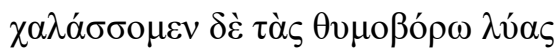

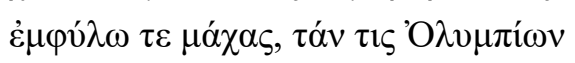

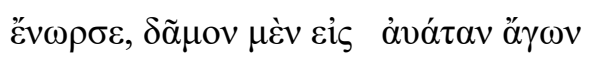

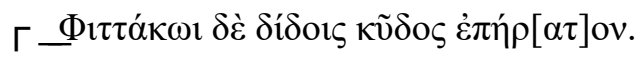

Decir, primero, estas cosas [...]

suena, participando del banquete [...]

el barbitón, junto con fanfarrones gan [dules]

festejando, que con ellos [...]

pero aquél, desposado con los Atridas,

que devore la ciudad, como también lo bizo con Mirsilo,

hasta que quiere Ares [a las armas]

volcarnos, ojalá pudiéramos olvidar esta furia,

calmemos la sedición que corroe nuestro ánimo

y las luchas civiles que uno de los Olimpicos

avivó, conduciendo al pueblo a la ofuscación

$y$ dando a Pítaco su amada reputación ${ }^{69}$

Sin mencionar la temida stásis, Alceo se sumerge en la riqueza conceptual del término $\lambda u ́ a \varsigma$ para señalar la discordia y la disidencia política, para luego dar cuenta

68 Gentili (1996: 405).

69 Alc. Fr. 70 LP 2-13. Trad. B. Berruecos. 


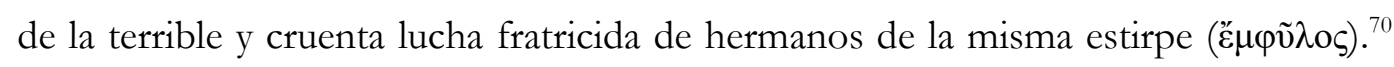
La corrosiva sedición empujada por Ares, lleva de manera indeclinable al $\delta \tilde{\alpha} \mu o v$ ó $\gamma \omega v$ en Mitilene, y el triunfo nuevamente de la tiranía.

Arquíloco de Paros, padre del yambo, ${ }^{71}$ utiliza la alegoría de la nave del Estado $^{72}$. No obstante no es posible atribuir los fragmentos conservados a la discordia civil, sino a las campañas militares en Tasos contra los tracios, en la que él participó como mercenario. Carmine Catenacci establece que "sus yambos no pretenden ensalzar los horizontes de gloria como la épica homérica, tampoco la urgencia moral e histórica de Calino. La muerte en batalla no es bella, como en la elegía de Tirteo, ni tampoco cobra el sentido que le atribuyó Alceo, que buscaba vanamente reafirmar en la guerra civil su privilegio social y político. La guerra es cantada por Arquíloco como una realidad concreta con énfasis en la dureza de la vida militar, y como horizonte cotidiano de su propia existencia". ${ }^{73}$ Siguiendo las influencias de su tiempo, al igual que Hesíodo, Arquíloco utiliza también elementos retóricos como la fábula de animales con una función ejemplar en forma agonal. ${ }^{74}$

Jenófanes de Colofón, a caballo entre el siglo VI y el siglo V a.C. recuerda en el espacio político del simposio que un hombre virtuoso no debe entrar en luchas intestinas.

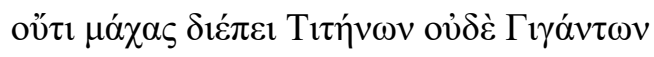

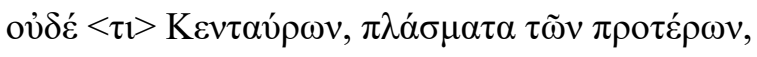

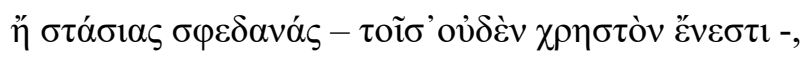

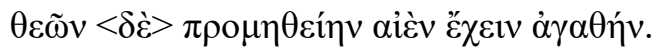

${ }^{70}$ Este término es usado por primera vez en Hom. Od. XV. 273. luego en Hes. Fr. 190. 2. Finalmente en las elegías de Alceo y Solón. No es común en la poesía arcaica.

${ }^{71}$ Catenacci (2017: 49 y 53). I versi fanno emergere, com’è noto, una novità nella storia della cultura occidentale. L' io del poeta è il protagonista. Archiloco è il capostipite di una figurra che avrà grande fortuna nella storia e nell'immaginario: il poeta soldato.

72 Archil. Fr. 56 D. Rodríguez Adrados (1955: 210) La problemática del tema de la nave del estado arranca de que, nacido en un poema determinado de Arquíloco, se ha aplicado luego a otras circunstancias diferentes.

${ }^{73}$ Catenacci (2017: 54 y 67).

${ }^{74}$ Gentili (1991: 401). 


\title{
TALIA DIXIT 15 (2020), 1-31
}

No entra en batallas de Titanes o Gigantes, ni tampoco de Centauros - ficciones de los antiguos - ni en las violentas reyertas: ningún bien hay en ellas; pero si de tener una reverencia, siempre buena, para con los dioses. ${ }^{75}$

Además de Hesíodo, Tirteo, Alceo y Jenófanes, se han conservado fragmentos de escolios o canciones de banquete que dan cuenta de la vida del simposio. La riqueza de estos fragmentos es que representan voces anónimas, ya sean aristocráticas o no, en donde la stásis ocupa un lugar preponderante en la vida política. Este es el caso de los Carmina Convivalia Attica, en versos eolocoriámbicos:

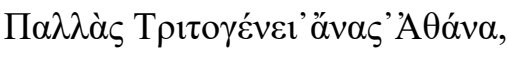

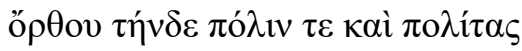 \\ $\dot{\alpha} \tau \varepsilon \rho \dot{\alpha} \lambda \gamma \varepsilon \dot{\varepsilon} \omega v \kappa \alpha \grave{~} \sigma \tau \alpha \dot{\sigma} \sigma \varepsilon \omega v$

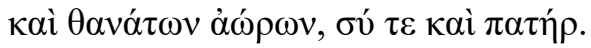 \\ Palas Tritogenia, señora Atenea, \\ endereza el rumbo de esta ciudad y de sus ciudadanos \\ sin dolores y luchas intestinas \\ y muertes a destiempo, tú y tu padre $e^{76}$.
}

La guerra que invierte el ciclo natural de la vida, donde los padres sepultan a sus hijos, ${ }^{77}$ es un tópico recurrente durante la primera parte del siglo $\mathrm{V}$ a. $\mathrm{C}$, y estos versos anónimos de camaradería dan cuenta del dolor de la muerte en las luchas civiles atenienses.

\section{Solón y la rebelión popular}

Solón es una de las figuras políticas más relevantes de toda la era arcaica griega y uno de los Siete Sabios de la antigüedad. Su existencia, que puede datarse entre los años 640 y 560 a.C. coincide con una era turbulenta donde profundos cambios sociales y políticos, revierten el orden social tradicional y la aristocracia pierde terreno a favor de burguesías emergentes. ${ }^{78}$

De los textos conservados acerca del poeta y legislador, ninguno de sus autores que le conocieron directamente. En el siglo $\mathrm{V}$ a.C. la historiografía ateniense lo

\footnotetext{
75 Xenoph. 1D. 21. Trad. F. Rodríguez Adrados.

76 Fr. 884 PMG. Trad. F. García Romero.

77 Hdt. I, 87.

${ }^{78}$ García Romero (2017: 109).
} 


\section{TALIA DIXIT 15 (2020), 1-31}

descontextualiza o lo ignora abiertamente. ${ }^{79}$ En el siglo IV a.C. las polémicas ideológicas de esa época, incidieron en el intento de eliminar toda posibilidad de extremismo radical en sus reformas. ${ }^{80}$ En Aristóteles se advierte una mitologización, legendarización y construcción de un personaje en tanto nomoteta, reformador democrático y evergeta. ${ }^{81}$

El acceso al poder de Solón se produce en medio de una profunda crisis interna en Atenas, ${ }^{82}$ marcada por las consecuencias de las violentas leyes de Dracón y las severas condiciones de vida de los habitantes más pobres de la ciudad y sus agobiantes deudas.

En las elegías conservadas con la poesía del legislador, el problema de la stásis es recurrente, siendo una de sus principales causales la posesión injusta e inequitativa de la riqueza. ${ }^{83} \mathrm{El} \mathrm{libre} \mathrm{albedrío} \mathrm{y} \mathrm{la} \mathrm{\tau úx \eta} \mathrm{llevan} \mathrm{a} \mathrm{los} \mathrm{hombres} \mathrm{por} \mathrm{caminos} \mathrm{que}$ implican acciones peligrosas (xivסuvos) al no existir límites para la riqueza. ${ }^{84}$

La Eunomía, como hemos visto anteriormente, se transforma en una variante jurídica de la poesía arcaica, en la que Tirteo de Esparta fue su precursor. ${ }^{85} \mathrm{La}$ Eunomía de Solón en coherencia con la poesía griega arcaica y lo que ha sido denominado poesía y política de la exhortación ${ }^{86}$, coloca en evidencia los grandes males provocados por la v̋ßpıৎ de los ciudadanos de Atenas. Para Solón, estos males

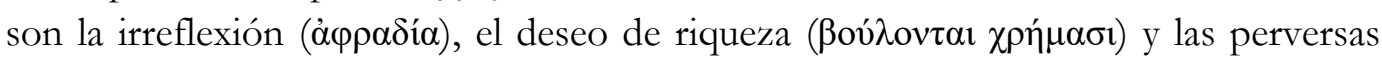

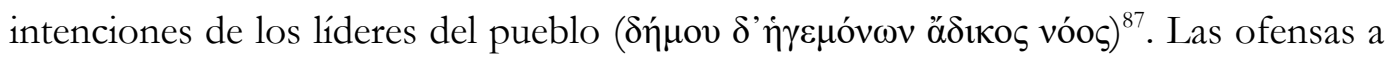

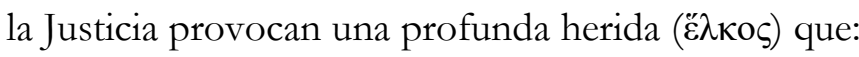

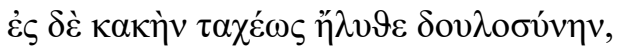

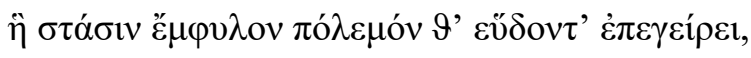

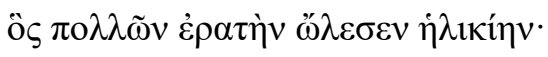

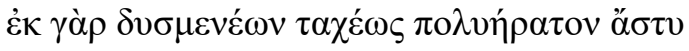

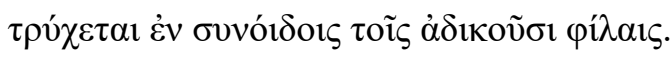

${ }^{79}$ Loddo (2018: 48 - 49).

${ }^{80}$ Manfredini - Piccirilli (2001: XVIII).

81 Loddo (2018).

82 Arist. Ath. Pol. 5, 2.

83 Sol. Elegías 1, 5.

84 Sol. Elegias 1, 65-70. Allan (2019: 136): "Solon is the earliest Greek thinker to analyse the dangers of an unlimited desire for wealth".

85 West (1974: 12).

86 Irwin (2005).

87 Allan (2019: 136 - 137): "Solon is part of a wider Archaic tradition criticizing the selfishness and luxury of aristocrats". 


\section{TALIA DIXIT 15 (2020), 1-31}

alcanza entonces a la ciudad entera: rápidamente cae en una infame esclavitud, que despierta las luchas civiles y la guerra dormida, fin de la hermosa juventud de muchos ciudadanos; que una hermosa ciudad es en breve arruinada a manos de sus enemigos en los conciliábulos de que gustan los malvados. ${ }^{88}$

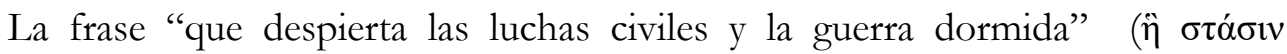

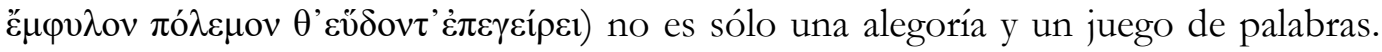
La guerra, entendida por Yvon Garlan como una "ley natural y una invención humana, como una pulsión espontánea y construcción jurídica", es un fenómeno permanente en la sociedad arcaica y se ajusta a las normativas interestatales que tenían las póleis. ${ }^{90}$ No así la stásis, que despierta la guerra dormida, con evidentes resonancias homéricas, ${ }^{91}$ poniendo de relieve un aspecto condenable de la lucha fratricida, que no se ajusta a las normas de convivencia ni humanidad: por ejemplo la relación entre el descanso del sueño nocturno y el asesinato en contexto de stásis, que desarrollará la tragedia ática del siglo $\mathrm{V}$ a.C. ${ }^{92}$ o el ataque a la población civil y la guerra urbana a causa de la stásis, sin regulación alguna y que conlleva generalmente la aniquilación total de los vencidos y sus familias. ${ }^{93}$ La muerte en juventud por motivos de la stásis ${ }^{94}$ no se eleva a la categoría heroica de Homero y Tirteo, sino que conlleva el terrible infortunio y la ruina de la ciudad.

Solón es enfático en señalar que este pernicioso escenario se produce por "la

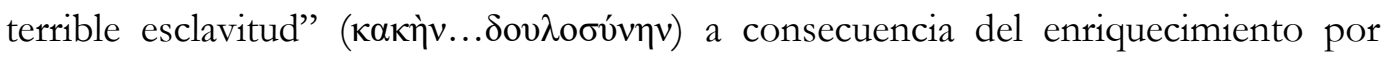
acciones injustas. ${ }^{95}$

El sesgo aristocrático dominante en Solón lleva a analizar el conflicto de la siguiente manera:

88 Sol. 3D, 15 - 20. Trad. F. Rodríguez Adrados.

89 Garlan (1972: 9).

90 Ténékidès (1993: 308 - 313): “Les méfaits de la guerre trop fréquemment déchaînée - et qui atteint cruellement la population rurale - amènera, par contre-coup, dans l'opinion, una tendance vers son "humanisation" et sa régularisation. La guerre devient sensiblement plus humaine durant la période hellénistique. Règles du droit de la guerre: Il est contraire au droit des gens d'attaquer sans déclaration de guerre; les ambassadeurs qui menaient les négotiations n'ont qu'un court délai, souvent vingt-quatre heures, pour quitter le pays; respecter les temples et les sanctuaires et, par voie de conséquence, à respecter ceux qui y cherchent asile.; Les prisonniers sont à la merci du capteur qui peut les passer au fil de l'épée ou les vendre comme esclaves; les dispositions de la capitulation laquelle est, juridicamente, une convention (homologia)- obligent également les deux parties: vainqueur et vaincu".

91 Hom. Il., XX, 31: “Así habló el Crónida y despertó un insondable combate”. Trad. E. Crespo.

92 Sommerstein (1993: 1-19). vid. Vlassopoulos - Xydopoulos (2017: 1).

93 Lee (2012: 142-145), vid. Gehrke (1997).

94 Tema recurrente en el simposio ático. Vs. Frag. 884 PMG Carmina Convivalia Attica.

95 Sol. 3D, 11. 


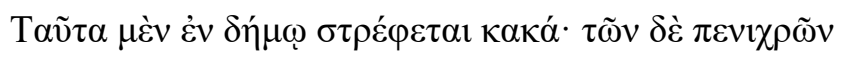

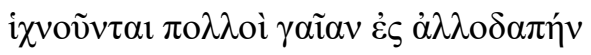

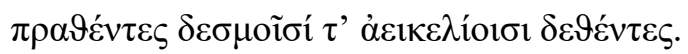

Éstas son las calamidades que se incuban en el pueblo; y, en tanto, muchos de los pobres llegan a una tierra extraña, vendidos y atados con afrentosas ataduras...... ${ }^{96}$

El desprecio por la pobreza se convierte en una verdadera doctrina en la poesía arcaica ${ }^{97}$ y Solón se siente llamado desde su propia posición social a ordenar el estado ateniense, renunciando a la tiranía, ${ }^{98}$ pero sin renunciar a la propia situación privilegiada.

La Eunomía, entendida como un código poético con fuerza moral es la solución para acallar a la Disnomía, fuente indeseada de la stásis:

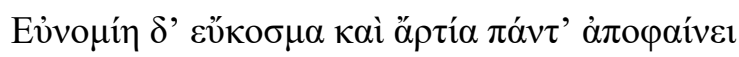

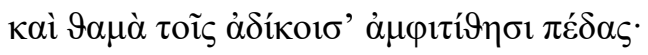

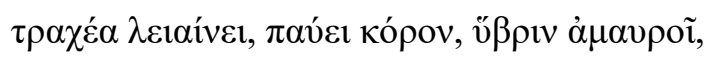

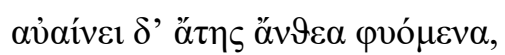

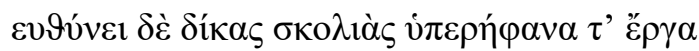

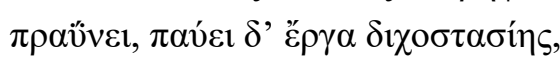

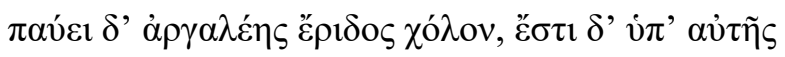

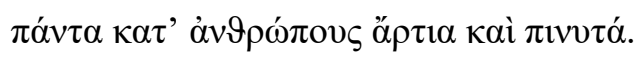

Eunomia lo hace todo ordenado cabal y con frecuencia coloca los grillos a los malvados: allana asperezas, pone fin a la hartura, acalla la violencia, marchita las nacientes flores del infortunio, endereza las sentencias torcidas y rebaja la insolencia, hace cesar la discordia, hace cesar el odio de la disensión funesta y bajo su influjo todas las acciones humanas son justas e inteligentes. ${ }^{99}$

No existe en toda la poesía arcaica un episodio más explícito respecto a la stásis y sus degradantes consecuencias para la vida ciudadana de la pólis.

96 Sol. 3D, 24-25. Trad. F. Rodríguez Adrados.

97 Cavallero (2001: 77): “Teognis desprecia la pobreza al igual que la riqueza si ambas conllevan a acciones injustas". Vid. Thgn., Elegías 173-181.

98 Sol. 23D, 10: (...) "respeté mi patria y no me entregué a la amarga violencia de la tiranía"; 23, 20: "no cometí locuras ni me place obrar por medio de la violencia de la tiranía". Trad. F. Rodríguez Adrados.

${ }^{99}$ Sol. 3D, 33-39. Trad. F. Rodríguez Adrados. 


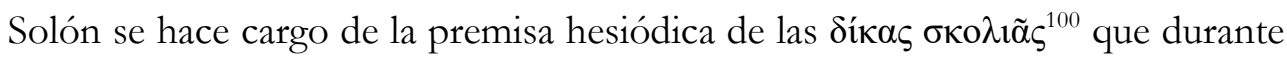
toda la era arcaica originó el conflicto social debido a la arbitrariedad de las sentencias y juicios torcidos de los magistrados y reyes devoradores de regalos. La Eunomía solónica pone fin a estas funestas prácticas que se asentaron al alero de la ley no escrita y la Disnomía. ${ }^{101}$ Las nociones de $\dot{\pi} \varepsilon \rho \eta ́ \varphi \alpha v \alpha$ y ö́n, no como divinidades sino como los infames instintos humanos de la arrogancia y la ruina fatal que engendra la violencia y la desmesura, caen subyugadas bajo el orden ( $\varepsilon \tilde{\kappa} \kappa o \sigma \mu \alpha)$.

Finalmente, Solón menciona la stásis, usando el énfasis adverbial de la

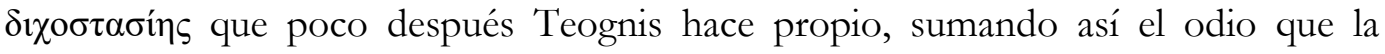
discordia humana y divina acarrean al interior de la sociedad (

En Solón, por lo tanto, se consagra una tradición poética arcaica que Hornblower ordena según cuatro grandes motivaciones, a saber, el dinero, la fama, el deseo de escribir y unir los mundos divinos y humanos haciendo del poema un himno a la divinidad. ${ }^{102}$

\section{Teognis y la disidencia aristocrática}

El poeta de Mégara es uno de los más importantes representantes del género elegíaco arcaico y de quien poseemos numerosos fragmentos. Las hipótesis sobre la causa de su desprecio hacia los pobres y su ruina resultan algunas más inverosímiles que otras. ${ }^{103}$ Como todo poeta de su tiempo, "Teognis es a la vez analista de la situación socio-política de su polis" ${ }^{104}$ Para Silvio Cataldi, los diálogos con Cirno, una imagen idealizada de la ciudad que debe ser reeducada en los valores aristocráticos, ${ }^{105}$

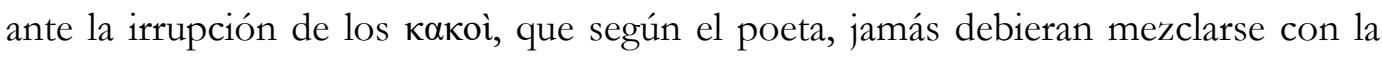
nobleza, ${ }^{106}$ posicionan a Teognis como el aedo de la exclusión y defensor de los valores de una nobleza en agonía.

100 También enunciadas en la Eunomía de Tirteo.

101 Leão y Rhodes (2016: 57-66) organizan las leyes solonianas contra las ofensas a la comunidad en donde el castigo legal de la atimía para la stásis y alta traición se evidencian en los fragmentos Fr. 37a; Fr. 37b; Fr. 38a; Fr. 38b; Fr. 38c; Fr. 38d; Fr. 38e; Fr. 38f; Fr. 38g; *Fr. 38h; *Fr. 38i; *Fr. 38j; †Fr. 38/1; †Fr. 38/m.

102 Hornblower (2009: 52)

103 Tausend (2013: 529-547) presenta distintas hipótesis que explican la miseria económica y la venalidad de Teognis. Entre ellas, la propia ambición, el fracaso en una expedición comercial, el exilio debido a la stásis en Mégara, hasta la proveniencia de un bajo estrato social y su imagen como escalador social. Cavallero (2001: 68-69), ubica al poeta megarense entre el 545 y 480 a.C, contemporáneo a Píndaro y una generación mayor que Esquilo, y coetáneo de los pisistrátidas y testigo de la conformación de la democracia ateniense.

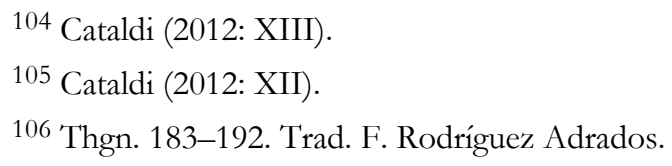




\section{TALIA DIXIT 15 (2020), 1-31}

La stásis se advierte ya en los primeros versos de sus elegías dirigidas a Cirno:

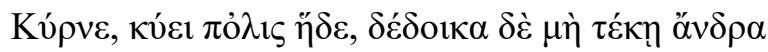

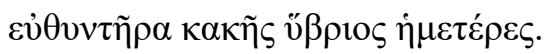

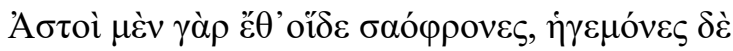

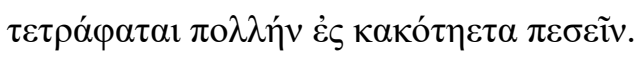

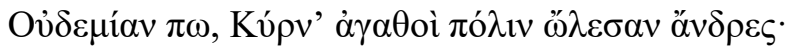

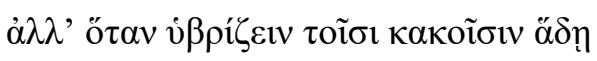

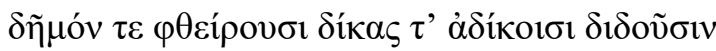

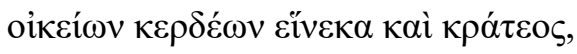

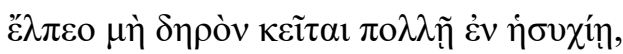

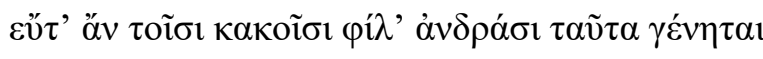

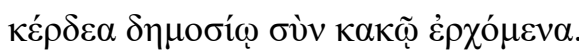

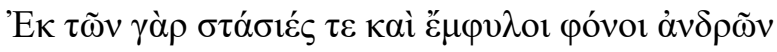

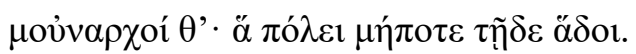

Cirno, esta ciudad está preñada y temo que para un hombre que enderece nuestro funesto desenfreno; pues los ciudadanos aún están sanos, pero los jefes han venido a caer en una gran vileza

Ninguna ciudad, ob Cirno, han arruinado aún los hombres de bien; mientras que cuando los malvados se deciden a mostrar su insolencia, corrompen al pueblo y le dan las sentencias a favor de los injustos para buscar ganancias y poderio propio, no esperes que esa ciudad, aunque abora esté en la mayor calma, permanezca tranquila por mucho tiempo una vez. que los malvados se aficionen a las ganancias con público perjuicio. De esto nacen las luchas civiles, las matanzas de ciudadanos y tiranos: iojalá no dé su voto a nada de ello esta ciudad! ${ }^{107}$

La ciudad como cuerpo político es uno de los primeros elementos que destacan de estos versos. Sabine Tausend interpreta este pasaje de Teognis sobre la pólis como un "organismo animado con terminología antropomórfica que dará luz a un vengador". ${ }^{108}$ Esta alegoría del cuerpo que da a luz a sus propios males posiciona a Teognis como un precursor del pensamiento político griego, ${ }^{109}$ aún cuando los

107 Thgn. 39-52. Trad. F. Rodríguez Adrados.

108 Tausend (2013: 534).

${ }^{109}$ Nagy (1984: 256): “Théognis assume effectivement une autorité morale parallèle è celle de législateurs comme Lycurgue et Solon". 


\section{TALIA DIXIT 15 (2020), 1-31}

males retratados sean sólo alegorías y poco se ajusten a los sucesos acaecidos en Megara. ${ }^{110}$

Contrariamente a lo que pudiera pensarse sobre el carácter anti-tiránico de las elegías y yambos arcaicos, Cataldi lee a un Teognis que no acusa a Teágenes de Mégara en este fragmento, sino que "advierte la posibilidad de un nuevo tirano, ya sea en su ciudad natal o en una amplia variedad de ciudades-estado, que se encontraban en situaciones políticas análogas a Mégara". ${ }^{111}$ Su poesía, según Gregory Nagy, sintetiza la tradición poética de Mégara, "poniendo en escena de manera muy efectiva la propia historia de Mégara a través de los siglos". ${ }^{112}$ El carácter panhelénico de su poesía presenta un nuevo elemento en los siguientes parágrafos de esta elegía, la naturaleza humana, el orden natural y el orden político:

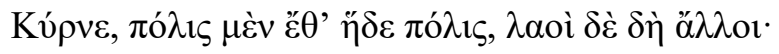

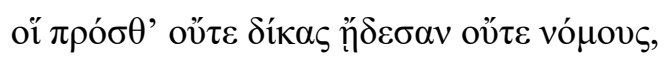

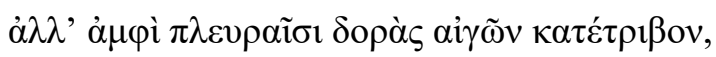

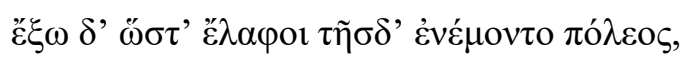

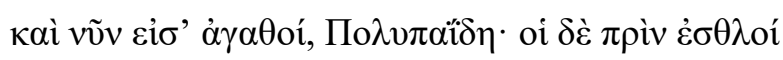

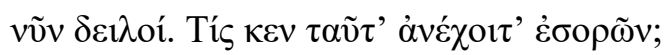

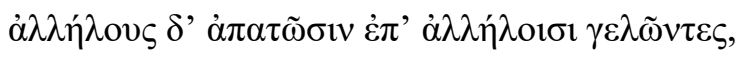

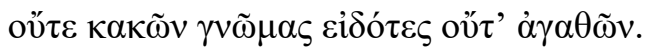

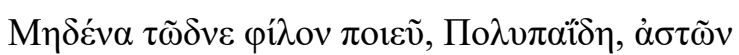

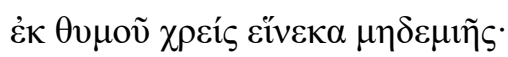

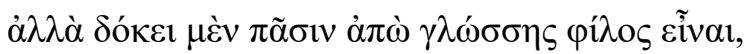

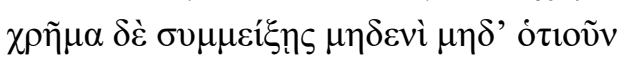

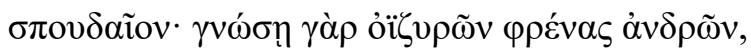

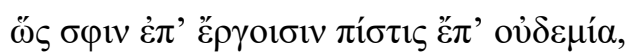

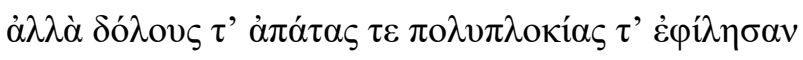

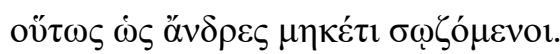

Cirno, esta ciudad es aun una ciudad, pero sus habitantes son abora distintos: antes, no conocian ni el derecho ni las leyes, sino que en torno a su cuerpo vestian pieles de cabra basta romperlas y se apacentaban, al igual que los ciervos, fuera de la ciudad. Éstas son hoy día las gentes de bien, ob Polipaides; y los buenos de antes, ahora son villanos: ¿quien es capaz de soportar este espectáculo? Se engañan unos a otros riéndose unos de otros, desconocedores de las

110 West (1974: 68): "But can those verses really be assumed to describe the growing excesses of the democracy? I venture to assert that they cannot. It is not that I advocate a blanket skepticism of any attempt to extract historical of biographical data from his remains. No less than the political poems of Solon and Alcaeus, they bear the stamp or real events, in principle identifiable".

111 Cataldi (2012: XIV).

112 Nagy (1984: 252). 


\section{TALIA DIXIT 15 (2020), 1-31}

normas para distinguir lo bueno de lo malo. A ninguno de estos ciudadanos hagas de su corazón tu amigo, Ob Polipaides, por causa de necesidad ninguna; por el contrario, procura parecer con tus palabras amigos de todos, peor no te unas con ninguno en ninguna empresa importante, porque entonces conocerás la manera de ser de estos miserables, cómo no tienen palabra en su comportamiento sino que gustan de los fraudes, los engaños y las trampas igual que los hombres irremediablemente perdidos. ${ }^{113}$

La noción teognidea de los tiempos pasados y de las costumbres de los antiguos habitantes permanece como un topos que recogerá la historiografía ática clásica. ${ }^{114}$ En esta sociedad binaria, en donde la maldad es atributo de quienes no

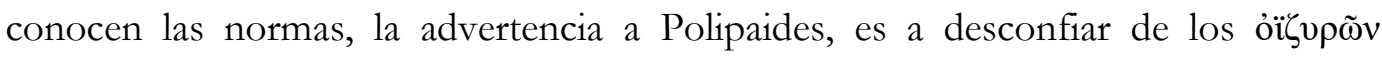

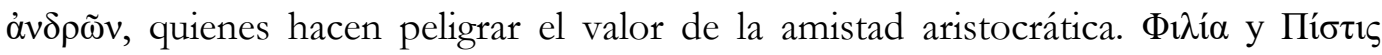
como valores de la sociedad arcaica ${ }^{115}$ en Teognis se ven amenazadas por los nuevos grupos sociales que irrumpen. Así ha de entenderse el siguiente parágrafo:

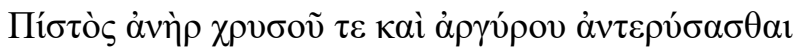

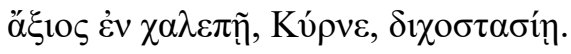

Un hombre leal es digno de ser pesado con oro y con plata, ob Cirno, en las terribles luchas civiles. ${ }^{116}$

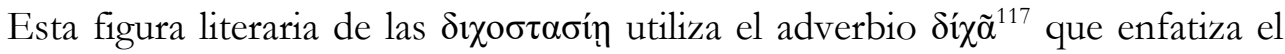
profundo impacto de la división que provocan las luchas fratricidas. En ese contexto la lealtad es escasa en la Mégara que presenta Teognis y protege a la sociedad de los conflictos internos y externos.

Las elegías teognideas contienen otras alusiones tales como las olas del mar que devoran las naves, como construcción retórica que alude a la stásis ${ }^{118} \mathrm{e}$ interpretada por Silvio Cataldi. ${ }^{119}$ Es visible entonces el permanente vínculo con la

113 Thgn. 53-68. Trad. F. Rodríguez Adrados.

114 FGrHist 1 F 119, Strab. VIII, 7, 1. "Casi la totalidad de Grecia fue en la antigüedad un asentamiento de bárbaros" vid. Donoso (2018) La sentencia de Hecateo inspira a Tucídides, quien en su Arqueología asocia estas costumbres arcaicas del uso de armas, la vestimenta, el desconocimiento de las leyes y la piratería en formas de barbarie interna.

115 Ferguson (2017: 55-56).

116 Thgn. 77-78. Trad. F. Rodríguez Adrados.

117 Liddell-Scott (1996: 438-439).

118 Thgn. 667-682. Trad. F. Rodríguez Adrados.

119 Cataldi (2012: XXVI): "Quanto alla metafora della nave in preda alla tempesta, attorno alla quale s'impernia l'ainos del poeta che vuole mandare un messaggio criptato ai suoi compagni di eteria che soli possono intenderlo, occorre qui osservare che, proprio a partire da questa immagine- 


\section{TALIA DIXIT 15 (2020), 1-31}

tradición literaria de la era arcaica y la nave del estado como potentísima imagen narrativa.

En la siguiente plegaria a Apolo, el escenario externo es gravitante en las amenazas a la que está expuesta Mégara si no logra controlar sus luchas intestinas. De esta manera debe leerse esta elegía:

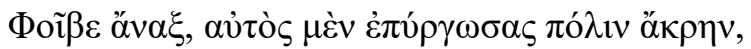

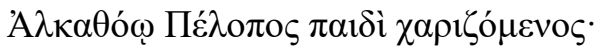

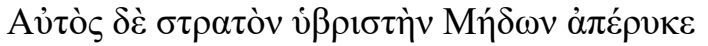

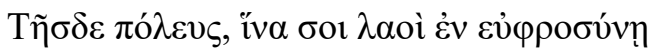

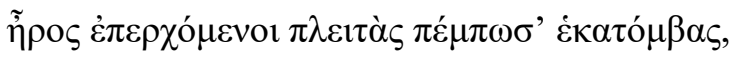

$\tau \varepsilon \rho \pi$ ó

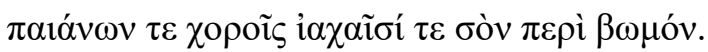

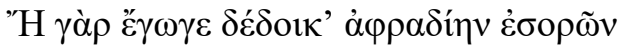

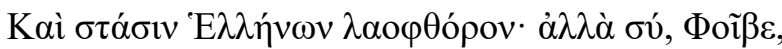

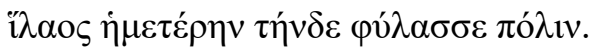

Febo rey, fuiste tú quien construyó la ciudadela para complacer a Alcátoo, el bijo de Pélope; sé tú mismo quien aleje de esta ciudad el salvaje ejército de los medos para que el pueblo, lleno de alegría, te sacrifique espléndidas hecatombes al comienzo de la primavera, mientras se siente regocijado, en torno a tu altar, por la citara y por la bermosa fiesta, por el baile y por el canto del peán y por los gritos. Porque en verdad, tengo miedo al ver la locura y la discordia suicida de los griegos; pero tú, Febo, sénos favorable y guarda esta ciudad. ${ }^{120}$

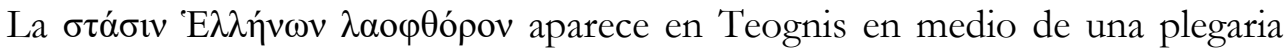
desesperada por la ruina de la ciudad. El pueblo que se autodestruye en revueltas civiles en el contexto de las primeras incursiones del ejército persa en Grecia, lleva a Rodríguez Adrados a interpretar el miedo de Teognis como suicidio de Mégara. Respecto a la amenaza Aqueménida, Rodríguez Adrados acepta como fecha las incursiones en Jonia del 545 a.C, ${ }^{121}$ pero hoy se admite la autoría de este episodio a

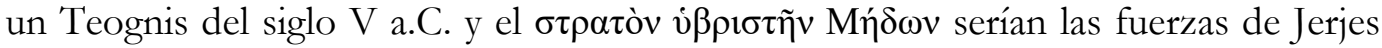
en las Termópilas el 480 a. C. ${ }^{122}$

En la última mención a la stásis en las elegías conservadas, el poeta megarense vuelve a presentar la alegoría de la temible gravidez:

chiave, ipostasi della città afflitta dalla discordia civile, l'elegia mette in scena la storia politica e sociale della polis".

120 Thgn. 773-782. Trad. F. Rodríguez Adrados.

121 Introducción a Thgn. (1959: 139).

122 Yates (2019: 183 y ss); Werlings (2010). 


\section{TALIA DIXIT 15 (2020), 1-31}

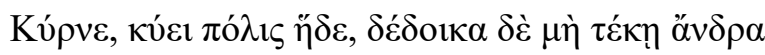

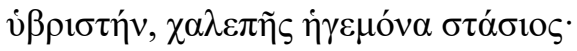

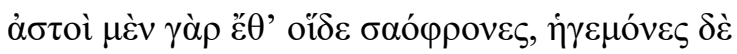

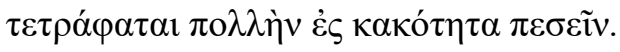

Cirno, esta ciudad está preñada y temo que para un hombre sin ley que acaudille una cruel revolución; porque estos ciudadanos aún están sanos, pero los jefes han venido a caer en una gran vileza. ${ }^{123}$

Aún cuando la apelación a Cirno es casi idéntica con los versos 39-42, el sentido no es necesariamente idéntico. Así lo evidencia Francisco Rodríguez Adrados cuando en el primer poema "un aristócrata teme que los excesos de sus compañeros de clase provoquen la llegada de la tiranía; en el segundo se teme simplemente a la

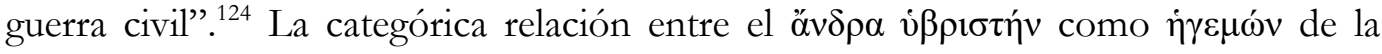
stásis debido a la maldad de los jefes y líderes políticos de la ciudad está directamente con el ciclo de la enfermedad, donde unos pocos enferman a la mayoría no contaminada.

Con pocas menciones explícitas de la stásis en las elegías de Teognis, el poeta logra transmitir una idea permanente de ruina y destrucción social en sus fragmentos conservados. Su voz se eleva como una llamada desesperada de una aristocracia en ruinas y a la vez una crítica a las clases sociales emergentes que han ocupado el lugar de los antiguos aristoi. Martin West ve a Alceo reflejado en Teognis como "un testigo aristocrático de una revolución demótica". ${ }^{125}$ Estas experiencias lo llevan a expresarse como un disidente aristocrático a través de alegorías tales como la ciudad preñada de maldad y la nave que se desfonda en el océano como potentes elementos retóricos que hacen de su elegía una dramática representación de la situación de Mégara, cuya proximidad con Atenas habría influido decisivamente en los procesos internos de esta ciudad. El panhelenismo de Teognis refleja lo que Hornblower define como una forma de liberación (poética) de la stásis, llevada a cabo por una gran parte de los poetas del siglo VI a. C. como un acto de paz al interior de las póleis. ${ }^{126}$

\section{Conclusiones}

La stásis como fenómeno político, endémico y estructural de la vida pública en la sociedad griega arcaica cobra especial sentido en los fragmentos poéticos de este

\footnotetext{
123 Thgn. 1081-1084. F. Rodríguez Adrados.

124 Introducción a Thgn. (1959: 104).

125 West (1974: 71)

126 Hornblower (2009: 55-56)
} 
período que han llegado hasta nosotros. A través de múltiples alegorías, los poetas elegíacos y yambógrafos construyen una noción del conflicto civil que no siempre es explícito. Hesíodo, como primer pensador social de Occidente y su idea matriz de los juicios, sentencias torcidas y reyes devoradores de regalos que alteran la paz social de la villa de Ascra, inspirará a la poesía aristocrática del siglo VII a. C. a continuar con esta idea en directa oposición a los regímenes tiránicos.

La stásis como fenómeno causado por la acumulación de riquezas, el provecho y sus formas de distribución comienza a desarrollarse a través del proceso reformista de las leyes de Solón. Sin embargo, la paz cívica está siempre condicionada a la necesidad de justicia y de sentencias justas de parte de los magistrados y a un pacto de convivencia al amparo de la ley escrita. De Tirteo a Solón se ponen de manifiesto en la poesía, como acto político, las distintas miradas que emanan desde el debate simposial. En este espacio aristocrático Alceo, Arquíloco y Jenófanes de Colofón recurren a fórmulas literarias que ocultan, redefinen y revierten el conflicto civil, traduciéndolo al lenguaje poético marítimo, religioso y bélico.

Solón y Teognis, en cambio, desde la elegía aristocrática del siglo VI a. C., asignan a la stásis un valor popular, en el contexto de los nuevos grupos sociales emergentes fruto de la prosperidad del comercio marítimo, donde una parte empobrecida de la población reclama asistencia y derechos que las populares tiranías no parecen resolver. Así, Solón como aedo y reformador ateniense compone la Eunomía buscando dar valor jurídico a un código poético y moral de convivencia cívica. Teognis, por su parte, desplazado de su aristocrática posición en la convulsa Mégara, denuncia las revueltas organizadas por jefes populares y tiranos en una ciudad preñada de maldad y destrucción.

Los fragmentos analizados refuerzan la idea de que la violencia política en el mundo arcaico no estaba supeditada a las masas populares, sino que, por el contrario, se concentraba particularmente en la aristocracia y en sus rencillas internas, que arrastraban a las facciones a entrar en conflicto. La voz en agonía de las poderosas aristocracias arcaicas se expresa a través de los poetas disidentes, que se niegan a asumir al proceso que coincide con el cambio de siglo y que invierten el protagonismo a la gran masa política. La stásis parece entonces un excelente recurso para exagerar las rencillas políticas con los tiranos o como símbolo de quiebre interno ante la irrupción del démos como nuevo actor político en las póleis griegas.

PAUlO DONOSO JOHNSON

Pontificia Universidad Católica de Valparaíso https:/ / orcid.org/0000-0002-4000-1468 


\section{BIBLIOGRAFÍA}

\section{Fuentes Primarias:}

Allan, W. (2019), Greek Elegy and Iambus. A Selection, Cambridge: University Press.

Alberto-Sanchi, L. (2020), Les Lettres Grecques. Anthologie de la littérature grecque d'Homère à Justinien, Paris: Les Belles Lettres.

Aristóteles (1988), Política, trad. Manuela García Valdés, Madrid: Editorial Gredos.

Aristóteles (2012), Constitución de los Atenienses, traducción de Inés Calero y Raúl Caballero, Madrid: Consejo Superior de Investigaciones Científicas.

Berruecos, B. (2018), Poesía Arcaica Griega (siglos VII-V a.C.), Tomo I, Ciudad de México: Bibliotheca Scriptorvm Graecorvm et Romanorvm Mexicana.

García Romero, F. (2017), De hombres y dioses. Antología de poesía lírica griega antigua (siglos VII - V a.C.), Madrid: Guillermo Escolar Editor.

Hesíodo (1962), Los Trabajos y los Días, trad. Fotios Malleros, Santiago de Chile: Editorial Universitaria.

Hesíodo (2006), Obras y Fragmentos, trad. A. Pérez Jiménez y A. Martínez Díaz, Madrid: Editorial Gredos.

Heródoto (1992), Historia, Tomo I, trad. Carlos Schrader, Madrid: Editorial Gredos.

Homero (2006), Ilíada, trad. Emilio Crespo, Madrid: Editorial Gredos.

Kirk, G.S., Raven, J. y Schofield, M. (2014), Los filósofos presocráticos. Historia crítica con selección de textos, trad. Jesús García Fernández, Madrid: Editorial Gredos.

Leão, F. D. y Rhodes, P. J. (eds.) (2016), The Laws of Solon, London y New York: I.B. Tauris.

Plutarco (2011), La vita di Solone, a cura di Mario Manfredini e Luigi Piccirilli, Milano: Fondazione Lorenzo Valla - A. Mondadori Editore.

Rodríguez Adrados, F. (1956 - 1959), Líricos Griegos. Elegíacos y Yambógrafos Arcaicos (siglos VII - V a.C.), II vols. Barcelona: Ediciones Alma Mater.

Tucídides (1990), Historia de la Guerra del Peloponeso I-II, trad. J. J. Torres Esbarranch, Madrid: Editorial Gredos.

West, M.L. (1974), Studies in Greek Elegy and Iambus, Berlin y New York: Walter de Gruyter. 


\section{TALIA DIXIT 15 (2020), 1-31}

Fuentes Secundarias:

Adkins, A.W.H. (1963), "Friendship and self-sufficiency in Homer and Aristotle", Classical Quarterly 13: 33-45.

Arancibia, J.P. (2020), "La stásis y la tragedia de la democracia”, HYBRIS. Revista de Filosofía 11: 79-111.

Berent, M. (1998), "Stasis, or the Greek invention of politics", History of Political Thought 19: 331-362.

Birgalias, N. (2012), "La possession de la terre: facteur de concorde et de paix au sein de la Cité, aux VII et Vie s. av. J.-C”, en S. Cataldi, E. Bianco y G. Cuniberti (eds.), Salvare le Poleis. Costruire la Concordia. Progettare la Pace, Alessandria: Edizioni dell'Orso, pp. 1-19.

Bottari, P. (1989) “Stasis: le mot grec, la chose romaine", Mètis. Anthropologie des mondes grec anciens 4: 87-100.

Cartledge, P. (1998), "Writing the history of archaic Greek political thought", en N. Fisher y H. Van Wees (eds.), Archaic Greece: New Approaches and New Evidence, London: Duckworth, pp. 782-824.

Cataldi, S. (2012), "L'onda inghiottirà la nave (Theogn. 680). Un percorso

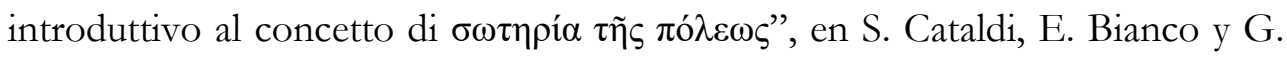
Cuniberti (eds.), Salvare le Poleis. Costruire la Concordia. Progettare la Pace, Alessandria: Edizioni dell'Orso, pp. IX-XXXVIII.

Catenacci, C. (2017), "Io, Archiloco, soldato e poeta", en A. Bonandini, E. Fabbro y F. Pontani (eds.), Teatri di Guerra. Da Omero agli ultimi giorni dell'umanità, Milano: Mimesis Edizioni, pp. 49-67.

Cavallero, P. (2001), “Teognis, un aristócrata ante el problema de la pobreza”, Circe, de Clásicos y Modernos 6: 65-80.

Chantraine, P. (1999), Dictionaire Étymologique de la Langue Grecque. Histoire des Mots, Paris: Klincksieck.

Colombani, M. C. (2018), "Hesíodo y las condiciones de un mundo habitable. Un ideal ecológico", De Rebus Antiquis 8: 1-16.

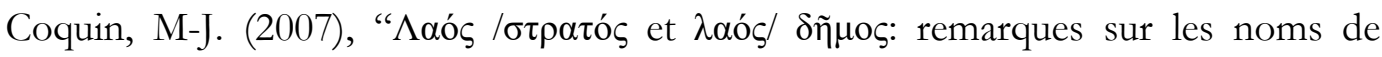
l'armée et du people dans l'Iliade", KTEMA. Civilisations de l'Orient, de la Grèce et de Roma Antiques 32: 459-465.

Courtieu, G. (2020), "La première revolution politique occidentale? (Odyssée IXXII)", Polis: The Journal for Ancient Greek and Roman Political Thought 37: 290-316.

D’Alessio, G.B (2009), “Defining local identities in Greek lyric poetry”, en R. Hunter 


\section{TALIA DIXIT 15 (2020), 1-31}

y I. Rutherford (eds.), Wandering Poets in Ancient Greek Culture. Travel, Locality and Panhellenism, New York: Cambridge University Press, pp. 137-167.

Diccionario Griego-Español (2009), Vol. VII, Madrid: Consejo Superior de Investigaciones Científicas.

Dimopoulou, A. (2019), "La violence politique à Lesbos à l'époque d'Alcée et Pittacos", Dialogues d'Histoire Ancienne 45: 23-36.

Donoso, P. (2018), "La barbarie interior en la Arqueología de Tucídides", Intus-Legere Historia 12: 246-268.

Dreher, M. (2009), "Stabilität und Gefährdung des spartanischen Kosmos”, en G. Urso (ed.), Ordine e Sovversione nel mondo greco e romano, Pisa: Edizioni ETS, pp. $39-67$.

Ferguson, J. (2017), Moral Values in the Ancient World, Londres: Routledge.

Finley, M. (1985), "War and Empire”, Ancient History: Evidence and Models, London: Chatto \& Windus.

Gabba, E. (2001), Storia e letteratura antica, Bologna: Il Mulino.

Gallego, J. (2006), "La imagen aldeana de la pólis: construcción de una identidad igualitaria de base agraria”, en D. Plácido, M. Valdés, F. Echeverría y Y.M. Montes (eds.), La construcción ideológica de la ciudadanía. Identidades culturales y sociedad en el mundo griego antiguo, Madrid: Editorial Complutense, pp. 67-86.

Gallego, J. (2017), La Polis griega. Orígenes, estructuras, enfoques, Buenos Aires: Editorial Facultad de Filosofía y Letras UBA.

Garlan, Y. (1972), La guerre dans l'antiquité, Paris: Editions Fernand Nathan.

Gehrke, H-J. (1997), "La stasis”, en S. Settis (ed.), I Greci. Storia, Cultura, Arte, Società. Una storia greca. Definizione (VI-IV secolo a.C.), Torino: Einaudi Editore, pp. 453476.

Gentili, B. (1996), Poesía y Público en la Grecia Antigua, Barcelona: Quaderns Crema.

Hansen, M.H. y Nielsen, T.H (eds.) (2004), An Inventory of Archaic and Classical Poleis, Oxford: Oxford University Press.

Harris, W. V. (1989), Ancient Literacy, Harvard: Harvard University Press.

Hornblower, S. (2009), "Greek lyric and the politics and sociologies of archaic and classical Greek communities”, F. Budelmann (ed.), The Cambridge Companion to Greek Lyric, New York: Cambridge University Press, pp. 39-71.

Iannucci, A. (2017), "Parole per la guerra: Omero, Tirteo e gli altri", en A. Bonandini, E. Fabbro y F. Pontani (eds.), Teatri di Guerra. Da Omero agli ultimi giorni dell'umanità, Milano: Mimesis Edizioni, pp. 23-47.

Irwin, E. (2005), Solon and Early Greek Poetry: The Politics of Exhortation, Cambridge: Cambridge University Press. 


\section{TALIA DIXIT 15 (2020), 1-31}

Konstan, D. (1997), Friendship in the Classical World, New York: Cambridge University Press.

Lee, J. W. (2012), “Guerra urbana en el mundo griego clásico”, en V. D. Hanson (ed.), El arte de la guerra en el mundo antiguo, Barcelona: Crítica, pp. 139-163.

Liddell H. G.-Scott, R. (1996), A Greek-English Lexicon, Oxford: Clarendon Press.

Lintott, A. (1982), Violence, Civil Strife and Revolution in the Classical City, Baltimore: John Hopkins University Press.

Loddo, L. (2018), Solone Demotikotatos. Il legislatore e il politico nella cultura democratica ateniese, Milano: Quaderni di Erga-Logoi.

Loraux, N. (1995), "La guerre civile grecque et la répresentation anthropolique du monde a l'envers", Revue de l'bistorie des religions 212, 3: 299-326.

Loraux, N. (2008), La guerra civil en Atenas: la politica entre la sombra y la utopía, Madrid: Akal.

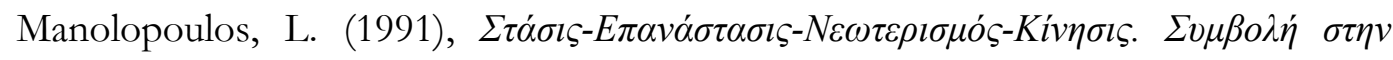

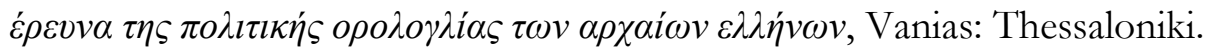

Mazzarino, S. (2011), Il pensiero storico classico, vol. I, Bari: Laterza.

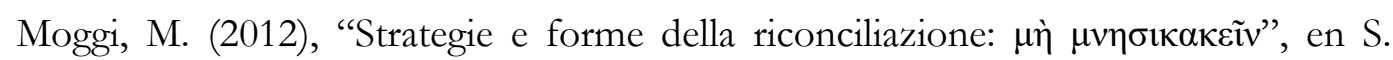
Cataldi, E. Bianco y G. Cuniberti (eds.), Salvare le Poleis. Costruire la Concordia. Progettare la Pace, Alessandria: Edizioni dell'Orso, pp. 133-160.

Montes Miralles, M. (2006), "Mecanismos de definición ideológica de la sociedad homérica” en D. Plácido, M. Valdés, F. Echeverría y Y.M. Montes (eds.), La construcción ideológica de la ciudadanía. Identidades culturales y sociedad en el mundo griego antiguo, Madrid: Editorial Complutense, pp. 33-43.

Nagy, G. (1984), “Théognis et Mégare. Le poète dans l'âge de fer”, Revue de l'histoire des religions 201: 239-279.

Radici, P. y Sergi, E. (2000) " $\Sigma T A \Sigma I \Sigma$ nel lessico politico greco", Annali della Scuola Normale Superiore di Pisa 5: 223-236.

Rodríguez Adrados, F. (1955), "Origen del tema de la nave del estado en un papiro de Arquíloco (fr. 56 A Diehl)”, Aegyptus 34: 206-210.

Shipley, G. (1993), “The limits of war”, en J. Rich. y G. Shipley (eds.), W ar and Society in The Greek World, London: Routledge, pp. 1-24.

Signes Codoñer, J. (2010), Escritura y literatura en la Grecia arcaica. Madrid: Akal.

Sommerstein, A, H. (1993), "Sleeping safe in our beds: stasis, assassination and the Orestia", en J. H. Molyneux (ed.), Literary Responses to Civil Discord, Nottingham: Classical Literature Studies 1, pp. 1-19.

Ste. Croix, G.E.M. (1988), La lucha de clases en el mundo griego antiguo, Barcelona: Editorial Crítica. 


\section{TALIA DIXIT 15 (2020), 1-31}

Stolfi, E. (2012), “Immagini della guerra nell’antica Grecia: stásis, pólemos e díkaios pólemos", Rivista di Studi Militari 1: 7-46.

Stolfi, E. (2020), La cultura giuridica dell'antica Grecia. Legge, politica, giustizia, Roma: Carocci Editore.

Tausend, S. (2013), “Theognis - Bankrotteur oder Stasis-Opfer?”, en R. Breitwieser, M. Frass y G .Nightingale (eds), Calamus. Festschrift für Herbert Graßl zum 65, Wiesbaden: Geburtstag, pp. 529-548.

Ténékidès, G. (1993), Les Relations Internationales dans la Grèce Antique, Athènes: Fondation A. G. Leventis.

Valdés Guía, M. (2019), "War in Archaic Athens: polis, Elites and Military power", Historia: Zeitschrift fur alte Geschichte 68: 126-149.

Van Wees, H. (2008), "Stásis, Destroyer of Men. Mass, Elite, Political Violence and Security in Archaic Greece", en C. Brélaz y P. Ducrey (eds.), Sécurité collective et ordre public dans les sociétés anciennes, Geneve: Fondation Hardt, pp. 1-48.

Vetta, M. (1992), "Il simposio: la monodia e il giambo", en G. Cambiano, L. Canfora y D. Lanza (eds.), Lo spąio letterario della Grecia antica, Vol I, Roma: Salerno Editrice, pp. 117-218.

Welskopf, E.C. (1985), Soziale Typenbegriffe. Belengstellenverzeichnis altgriechischer sozialer Typenbegriffe von Homer bis Aristoteles, Berlin: Akademie Verlag.

Werlings, M.-J. (2010), Le demos avant la démocratie. Mots, concepts, réalités historiques, Nanterre: Presses Universitaires de Paris Nanterre.

Wilamowitz-Moellendorff, U. (1912), Die griechische Literature des Altertums, Leipzig: B.G. Teubner.

Xydopoulos, I., Vlassopoulos, K. y Tounta, E. (2017), Violence and Community. Law, Space and Identity in the Ancient Eastern Mediterranean World, London y New York: Routledge.

Yates, D. C. (2019), States of Memory. The Polis, Panhellenism and The Persian Wars, Oxford: Oxford University Press. 